\title{
Hap2-Ino80-facilitated transcription promotes de novo establishment of CENP-A chromatin
}

\author{
Puneet P. Singh, ${ }^{1}$ Manu Shukla, ${ }^{1}$ Sharon A. White, ${ }^{1}$ Marcel Lafos, ${ }^{1}$ Pin Tong, ${ }^{1,3}$ \\ Tatsiana Auchynnikava, ${ }^{1}$ Christos Spanos, ${ }^{1}$ Juri Rappsilber, ${ }^{1,2}$ Alison L. Pidoux, ${ }^{1}$ and \\ Robin C. Allshire ${ }^{1}$ \\ ${ }^{1}$ Wellcome Centre for Cell Biology, School of Biological Sciences, The University of Edinburgh, Edinburgh EH9 3BF, United \\ Kingdom; ${ }^{2}$ Bioanalytics, Institute of Biotechnology, Technische Universität Berlin, 13355 Berlin, Germany
}

Centromeres are maintained epigenetically by the presence of CENP-A, an evolutionarily conserved histone $\mathrm{H3}$ variant, which directs kinetochore assembly and hence centromere function. To identify factors that promote assembly of CENP-A chromatin, we affinity-selected solubilized fission yeast CENP-A ${ }^{\text {Cnp1 }}$ chromatin. All subunits of the Ino80 complex were enriched, including the auxiliary subunit Hap2. Chromatin association of Hap2 is Ies4-dependent. In addition to a role in maintenance of CENP-A ${ }^{\mathrm{Cnp} 1}$ chromatin integrity at endogenous centromeres, Hap2 is required for de novo assembly of CENP- $\mathrm{A}^{\mathrm{Cnp} 1}$ chromatin on naïve centromere DNA and promotes $\mathrm{H} 3$ turnover on centromere regions and other loci prone to CENP-A ${ }^{\text {Cnp1 }}$ deposition. Prior to CENP-A ${ }^{\text {Cnp1 }}$ chromatin assembly, Hap2 facilitates transcription from centromere DNA. These analyses suggest that Hap2-Ino80 destabilizes $\mathrm{H} 3$ nucleosomes on centromere DNA through transcription-coupled histone $\mathrm{H} 3$ turnover, driving the replacement of resident $\mathrm{H} 3$ nucleosomes with CENP-A ${ }^{\text {Cnp1 }}$ nucleosomes. These inherent properties define centromere DNA by directing a program that mediates CENP-A ${ }^{\mathrm{Cnp1}}$ assembly on appropriate sequences.

[Keywords: CENP-A; centromere; chromatin; chromosome segregation; epigenetic; fission yeast; histone; kinetochore; remodeling; transcription]

Supplemental material is available for this article.

Received September 9, 2019; revised version accepted December 11, 2019.

The accurate delivery of all chromosomes to both resulting nuclei during mitotic cell division is required for eukaryotic cell viability and to prevent aneuploidy, a hallmark of cancer (Kops et al. 2005). The centromere region of chromosomes mediates their attachment to spindle microtubules for normal mitotic chromosome segregation (Fukagawa and Earnshaw 2014). In many organisms, centromeres are assembled on repetitive elements such as $\alpha$-satellite repeats, minor satellite repeats, cen180/CentC/ CentO repeats, and retroelements at human, mouse, plant, and Drosophila centromeres, respectively (Kipling et al. 1991; Grady et al. 1992; Cheng et al. 2002; Chang et al. 2019). Although such centromere repeats lack sequence similarity, in many cases their introduction as naked DNA into cells triggers de novo kinetochore assembly (Baum et al. 1994; Okada et al. 2007).

\footnotetext{
${ }^{3}$ Present address: MRC Human Genetics Unit, Institute of Genetics and Molecular Medicine, University of Edinburgh, Edinburgh EH4 2XU, United Kingdom.

Corresponding author: robin.allshire@ed.ac.uk

Article published online ahead of print. Article and publication date are online at http://www.genesdev.org/cgi/doi/10.1101/gad.332536.119. Freely available online through the Genes \& Development Open Access option.
}

The underlying conserved feature at eukaryotic centromeres is the assembly of nucleosomes containing the histone H3 variant CENP-A (also generally known as cenH3, and specifically as CID in Drosophila, Cse4 in Saccharomyces cerevisiae, and Cnp1 in Schizosaccharomyces pombe) in place of canonical H3 to direct kinetochore assembly on such repetitive elements. Moreover, it is known that following deletion of an endogenous centromere, CENP-A incorporation and neocentromeres can arise at novel noncentromeric DNA locations (Ishii et al. 2008; Ketel et al. 2009; Shang et al. 2013). CENP-A chromatin has also been shown to be sufficient to trigger kinetochore assembly (Barnhart et al. 2011; Mendiburo et al. 2011; Hori et al. 2013; Chen et al. 2014). Thus, CENP-A deposition and not the primary sequence of centromere DNA determines the position of centromere formation. However, centromere DNA itself may harbor properties that favor CENP-A and kinetochore assembly (Baum et al. 1994; Fachinetti et al. 2015; Logsdon et al. 2019).

(c) 2020 Singh et al. This article, published in Genes \& Development, is available under a Creative Commons License (Attribution 4.0 International), as described at http://creativecommons.org/licenses/by/4.0/. 
Three fission yeast species possess complex regional centromeres in which CENP-A ${ }^{\text {Cnp1 }}$ and kinetochores are assembled over a nonrepetitive central domain of $\sim 10 \mathrm{~kb}$ in $S$. pombe, S. octosporus, and S. cryophilus (Tong et al. 2019). Although flanking gene order is preserved, the central domain sequence is not conserved among these species. Despite this lack of similarity, central domain DNA from $S$. octosporus and $S$. cryophilus, as well as $S$. pombe, can direct de novo CENP-A ${ }^{\text {Cnp1 }}$ and kinetochore assembly in S. pombe (Folco et al. 2008; Catania et al. 2015; Tong et al. 2019). This suggests that these nonhomologous centromere DNAs possess innate features that program events that preferentially trigger the assembly of CENP-A ${ }^{\mathrm{Cnp} 1}$ in place of $\mathrm{H} 3$ nucleosomes.

During replication, parental CENP-A has been shown to distribute equally to nucleosomes on duplicated DNA of both sister centromeres, thus halving the amount of CENP-A at each centromere (Jansen et al. 2007; Schuh et al. 2007). Replenishment by deposition of newly synthesized CENP-A is temporally separated from DNA replication-coupled $\mathrm{H} 3$ chromatin assembly. The timing of new CENP-A deposition differs in various species; mitosis/late telophase/early G1 in human and Drosophila (Schuh et al. 2007; Erhardt et al. 2008; Mellone et al. 2011), S phase in S. cerevisiae (Pearson et al. 2004), and G2 in plants and S. pombe (Lermontova et al. 2006; Shukla et al. 2018).

Several studies have reported the association of RNA polymerase II (RNAPII) with and/or transcription from CENP-A-associated DNA so that noncoding transcription has become an apparent integral feature of centromeres (Duda et al. 2017). RNAPII has been detected at human artificial chromosome (HAC) (Bergmann et al. 2011), human metaphase (Chan et al. 2012), Drosophila (Bobkov et al. 2018), and S. cerevisiae (Ohkuni and Kitagawa 2011) centromeres, and also the central domains of fission yeast centromeres (Choi et al. 2011; Catania et al. 2015). Disruption of centromere transcription appears to hinder CENP-A loading and/or maintenance (Nakano et al. 2008; Bergmann et al. 2011; Chen et al. 2015; McNulty et al. 2017; Ling and Yuen 2019). Moreover, increased centromere transcription results in the rapid loss of CENP-A and centromere function (Hill and Bloom 1987; Bergmann et al. 2012). The central CENP-A ${ }^{\text {Cnp1 }}$ domains from $S$. pombe centromeres contain numerous RNAPII transcriptional start sites and promoters (Choi et al. 2011; Catania et al. 2015). In addition, ectopically located central domain DNA, which lacks CENP-A ${ }^{\text {Cnp1 }}$ chromatin, exhibits high rates of histone H3 turnover (Shukla et al. 2018). Such observations suggest that transcriptioncoupled chromatin remodeling events might drive the eviction of $\mathrm{H} 3$ and its replacement with CENP-A ${ }^{\text {Cnp1 }}$. Consistent with this view, the accumulation of elongating RNAPII on ectopic centromere DNA during G2 coincides with the eviction of $\mathrm{H} 3$ and deposition of new CENP-A (Shukla et al. 2018). However, it remains to be determined which transcription-associated chromatin remodeling factors provoke the replacement of $\mathrm{H} 3$ with CENP-A on naïve centromere DNA.
Various ATP-dependent chromatin remodeling complexes provide access to the underlying DNA of chromatin-coated templates. Their activities enable transcription by disassembling nucleosomes, sliding nucleosomes, or replacing nucleosomal histone subunits with transcription-promoting variants (Clapier and Cairns 2009). The remodeling and spacing factor (RSF) interacts with CENP-A chromatin in mid-G1, its depletion reduces CENP-A levels at centromeres (Perpelescu et al. 2009), and tethering of RSF1 to centromere repeats promotes histone turnover/exchange resulting in both H3.3 and CENPA deposition (Ohzeki et al. 2016). In S. pombe, Hrp1 (ortholog of chromo-helicase DNA-binding protein 1 [CHD1]) is enriched at centromeres and is required to maintain normal CENP-A ${ }^{\text {Cnp1 }}$ levels at centromeres (Walfridsson et al. 2005; Choi et al. 2011). Loss of the histone chaperone facilitates chromatin transcription (FACT) results in promiscuous CENP-A ${ }^{\text {Cnp1 }}$ assembly at noncentromeric locations $A^{\text {Cnp1 }}$ (Choi et al. 2012), suggesting that CENP-A ${ }^{\text {Cnp1 }}$ may be titrated away from centromeres by loss of such factors. Moreover, inducible ectopic centromeres in Drosophila requires FACT-mediated RNAPIIdependent transcription of underlying DNA, indicating a necessity for transcription during CENP-A assembly (Chen et al. 2015).

Ino80 is a Snf2 family ATPase evolutionarily conserved from yeast to humans that participates in transcription, DNA replication, and DNA repair (Conaway and Conaway 2009). The Ino80 complex (Ino80C) can slide nucleosomes in an ATP-dependent manner (Chen et al. 2011) and can space multiple nucleosomes on longer DNA fragments (Udugama et al. 2011). Ino80C may also remove H2A.Z-H2B dimers from nucleosomes, replacing them with H2A-H2B dimers (Papamichos-Chronakis et al. 2011; Brahma et al. 2017). H2A.Z is enriched in +1 nucleosomes downstream from promoters of many active genes, and loss of Ino80 function affects transcription (Hogan et al. 2010; Marques et al. 2010; Xue et al. 2015). Individual Ino80C subunits make up three modules that associate with the main Ino80 ATPase subunit (Supplemental Table S1; Chen et al. 2011). S. pombe Ino80 has been shown to influence the maintenance of CENP$\mathrm{A}^{\mathrm{Cnp} 1}$ chromatin at centromeres (Choi et al. 2017). However, it is not known whether Ino80C influences centromere DNA transcription or the establishment of CENP-A chromatin on naïve centromere DNA and, thus, centromere identity.

Here we used affinity selection of CENP-A ${ }^{\text {Cnp1 }}$ chromatin and mass spectrometry to identify proteins enriched in CENP-A ${ }^{\text {Cnp1 }}$ chromatin that may promote CENP-A ${ }^{\text {Cnp1 }}$ assembly. We identify Hap2 (SPCC16C4.20) as an auxiliary subunit of Ino80C that is required for the conversion of H3 chromatin to CENP-A ${ }^{\text {Cnp1 }}$ chromatin on naïve centromere DNA. We show that loss of Hap2 function reduces transcription and histone $\mathrm{H} 3$ turnover on centromere DNA. Our findings indicate that Hap2-Ino80 is required to promote transcription-associated chromatin remodelling events that drive $\mathrm{H} 3$ nucleosome eviction and the assembly of CENP-A ${ }^{\text {Cnp1 }}$ nucleosomes in their place. 
Singh et al.

\section{Results}

Hap2 is an Ino80C subunit that is enriched in CENP-A $A^{\text {Cnp } 1}$ chromatin

To identify proteins involved in the assembly of CENP-A ${ }^{\text {Cnp1 }}$ chromatin, GFP-tagged CENP-A ${ }^{\text {Cnp1 }}$ chromatin was affinity-purified from micrococcal nuclease (MNase)-solubilized chromatin extracts (Fig. 1A). Quantitative PCR (qPCR) analysis of the resulting enriched native chromatin revealed significant enrichment of centromeric DNA from the single-copy central CENP-A ${ }^{\text {Cnp1 }}$ domain of cen2 (cc2) compared with the 18 copies of flanking outer repeat $(d g)$ sequences (Supplemental Fig. S1A). In addition, SDS-PAGE analysis showed core histones to be prevalent in this affinity-selected GFP-CENP-A ${ }^{\text {Cnp1 }}$ material (Fig. 1B; Supplemental Fig. S1B). Label-free quantitative mass spectrometry detected strong enrichment of all known subunits of both the inner and outer kinetochore complexes (Fig. 1C; Supplemental Tables S2, S3). As our procedure also showed association of the chaperones Scm3 (HJURP) and Sim3 (NASP) that mediate CENP-A ${ }^{\text {Cnp } 1}$ deposition we reasoned that other enriched, but non-centromere-specific, proteins might be involved in the incorporation of CENP-A ${ }^{\mathrm{Cnp} 1}$ into centromeric chromatin.

It was notable that all subunits of the Ino80 chromatin remodeling complex (Ino80C) were enriched in our affinity-selected GFP-CENP-A ${ }^{\text {Cnp1 }}$ preparations (Fig. 1C).
Also enriched in these samples was the low-molecularweight $\alpha$-helical Hap2 protein. Hap2 has previously been reported to associate with Ino80C but no characterization has been performed (Hogan et al. 2010). To confirm association of Hap2 with Ino80C, Hap2 was C-terminally tagged with GFP at its endogenous chromosomal locus (Hap2-GFP) (Supplemental Fig. S2A). Affinity selection of Hap2-GFP followed by proteomic analysis revealed that all subunits of Ino80C, but not subunits of other remodelling complexes, are enriched with Hap2-GFP (Fig. 1D; Supplemental Table S4). IP-western analysis confirmed that Hap2-GFP associates with immunoprecipitated HA-tagged Ino80 (Ino80-HA) and vice-versa, independently of DNA/chromatin association (Supplemental Fig. S1C,D). Furthermore, affinity selection of Ino80-HA enriched all known Ino80C subunits along with Hap2 (Supplemental Fig. S1E; Supplemental Table S5). We conclude that Hap2 is a noncanonical subunit of the fission yeast Ino80 complex and that all Ino80C subunits are enriched in CENP-A ${ }^{\text {Cnp1 }}$ chromatin.

\section{Hap2 association with central domain DNA assembled in CENP-A ${ }^{\text {Cnp } 1}$ chromatin or H3 chromatin is Ies4-dependent}

Microscopic analysis showed that Hap2-GFP localizes to the nucleus (Fig. 2A). Quantitative chromatin immunoprecipitation (qChIP) assays revealed that Hap2-GFP

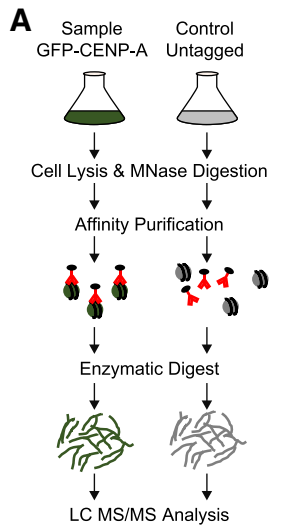

B

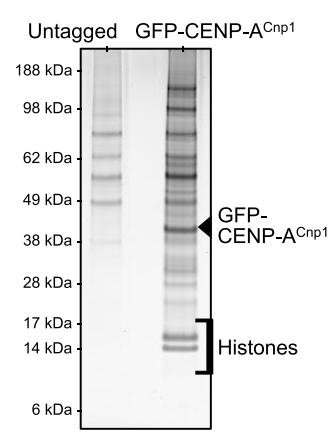

C

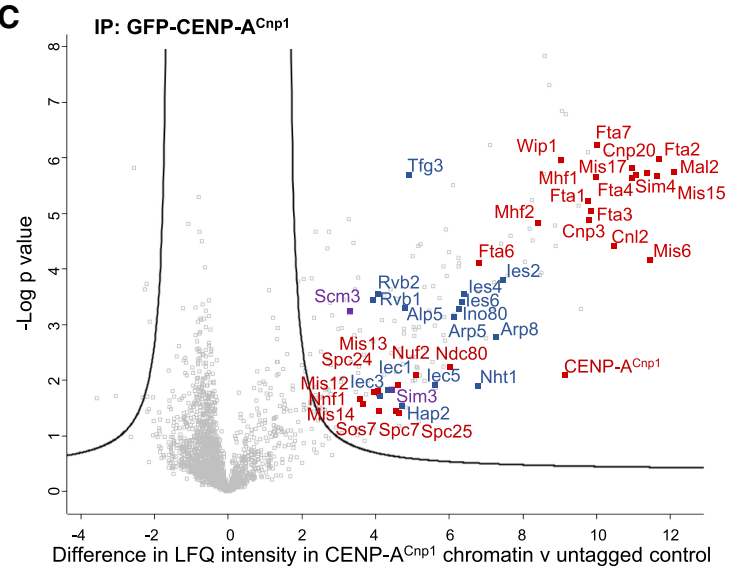

D

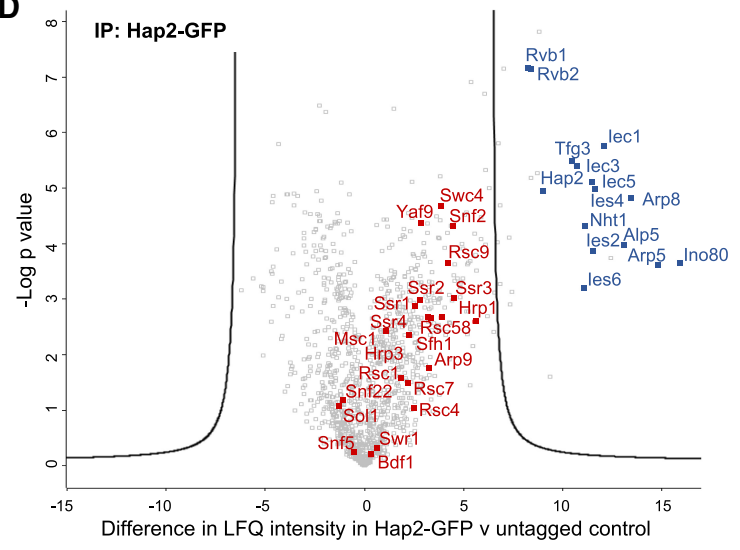

Figure 1. Hap2 is associated with CENP$\mathrm{A}^{\mathrm{Cnp} 1}$ chromatin and it is a subunit of Ino80C. (A) Scheme for enrichment of CENP-A ${ }^{\text {Cnp } 1}$ chromatin associated proteins and identification by mass spectrometry. (B) Silver-stained SDS-PAGE of proteins enriched in IPs from GFP-CENP-A ${ }^{\text {Cnpl }}$ or untagged control cells. (C) Volcano plot comparing label-free quantification (LFQ) intensity of proteins enriched in affinity selected GFP-CENP-A ${ }^{\text {Cnp1 }}$ (anti-GFP) versus untagged control. Inner and outer kinetochore proteins detected (red). Ino80C subunits (blue). CENP-A ${ }^{\text {Cnpl }}$ chaperones $\mathrm{Scm} 3$ and Sim3 (purple). (D) Volcano plot comparing label-free quantification of proteins enriched in affinity selected Hap2-GFP (antiGFP) versus untagged control. Ino80C subunits (blue). Swrl complex subunits, SWI/ SNF complex, RSC complex, and CHD family members (red). 
A

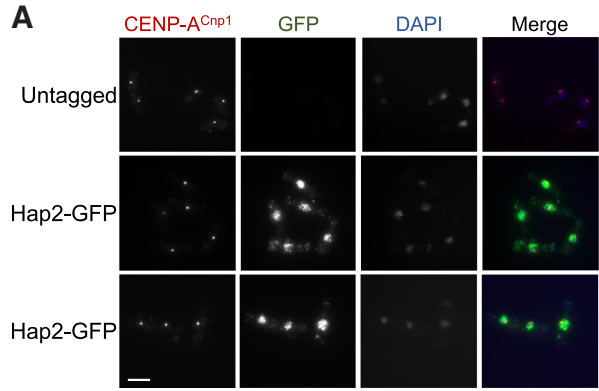

B

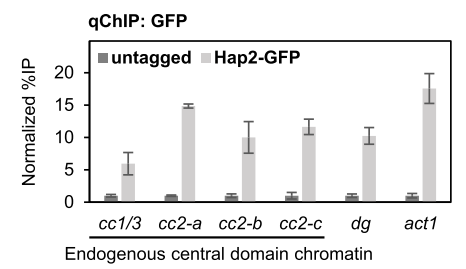

C
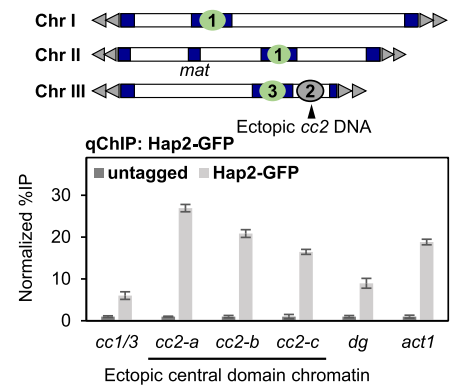

D

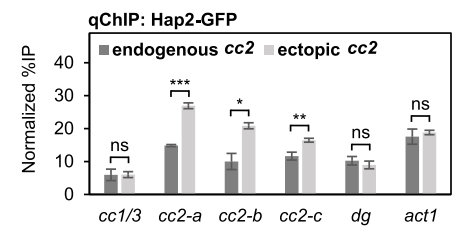

E

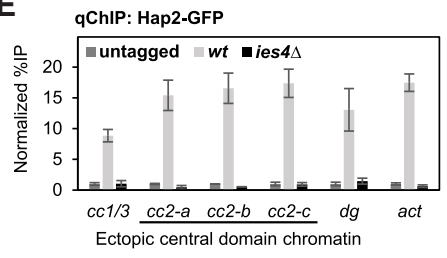

F

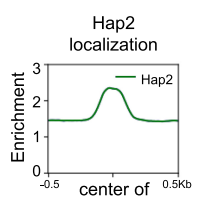

Arp5 peaks

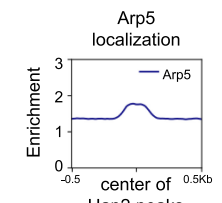

Hap2 peaks
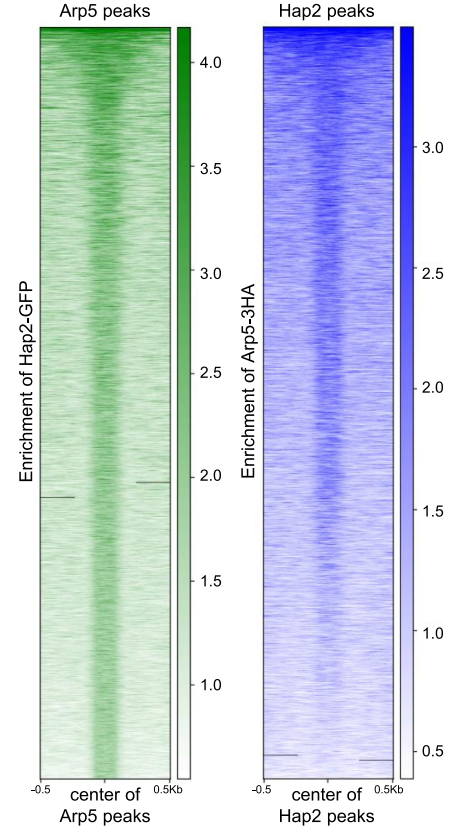

Figure 2. Hap2 associates with endogenous and ectopic central core chromatin and Ies4 dependent, Hap2 and Arp5 chromosomal distributions are coincident. $(A)$ Immunolocalization of Hap2-GFP in cells. Representative images of wild-type and Hap2-GFP cells stained with anti-CENP$\mathrm{A}^{\text {Cnp1 }}$ (red), anti-GFP (green), and DAPI (blue). Scale bar, $5 \mu \mathrm{m}$. (B) qChIP for Hap2GFP at four locations within endogenous centromeres $(c c 1 / 3, c c 2-a, c c 2-b$, and $c c 2$ $c)$, outer repeat heterochromatin $(d g)$ and noncentromere locus $\left(a c t 1^{+}\right)$. Error bars indicate mean $\pm \operatorname{SD}(n=3)$. (C, top $)$ Diagram indicating strain with endogenous cen2-cc2 replaced with cen1 central domain DNA (cc1) at the noncentromeric ura4 locus (ura4:cc2) on Chr III. (Bottom) qChIP for Hap2-GFP at three locations within ectopic central domain $\mathrm{H} 3$ chromatin $(c c 2-a, c c 2-b$, and $c c 2-c)$, endogenous centromeres $(c c 1 / 3)$, outer repeat heterochromatin $(d g)$, and noncentromere locus $\left(a c t 1^{+}\right)$. Error bars indicate mean $\pm \mathrm{SD}(n=3)$. $(D)$ Comparison of Hap2GFP association with central domain sequence assembled in CENP-A ${ }^{\text {Cnpl }}$ chromatin or $\mathrm{H} 3$ chromatin (data from $B$ and $C$ ). Error bars indicate mean \pm SD $(n=3)$. Significance of the differences observed between cells containing endogenous centromeres and ectopic central domain DNA was evaluated using Student's $t$-test. $\left({ }^{*}\right) P<0.05 ;\left({ }^{* *}\right) P$ $<0.005$; $\left.{ }^{* * *}\right) P<0.0005$; (n.s.) not significant. $(E)$ qChIP for Hap2-GFP at three locations within ectopic central domain $\mathrm{H} 3$ chromatin (cc2-a, $c c 2-b$, and $c c 2-c)$, endogenous centromeres $(c c 1 / 3)$, outer repeat heterochromatin $(d g)$ and noncentromere locus $\left(a c t 1^{+}\right)$in untagged, wild-type, and ies $4 \Delta$ cells. $(F)$ Genome-wide coincidence of Hap2-GFP and Arp5-3HA peaks ( 60\%). Gradient shows enrichment of Hap2 (green) and Arp5 (blue).

associates with most chromatin regions analyzed including the central CENP-A ${ }^{\text {Cnp1 }}$ domain of centromeres $(c c 2)$, the flanking pericentromeric outer repeats $(\mathrm{dg})$ and on the highly expressed $a c t 1^{+}$gene (Fig. 2B). When 8.5 $\mathrm{kb}$ of cen2 central domain DNA (cen2-cc2) is inserted at the ura4 locus on a chromosome arm (ura4:cc2), it is assembled in $\mathrm{H} 3$ instead of CENP-A ${ }^{\text {Cnp1 }}$ chromatin (Choi et al. 2012; Shukla et al. 2018). Replacement of $6.5 \mathrm{~kb}$ of endogenous cen2-cc2 DNA with $5.5 \mathrm{~kb}$ of cen1 central domain DNA (cc24::cc1) allows analysis across the resulting unique ectopic copy of cen2 central domain DNA (ura4:cc2) in the absence CENP-A ${ }^{\mathrm{Cnp} 1}$ and kinetochore proteins (Fig. 2C, top). qChIP analysis revealed that Hap2-GFP associates with this ectopic $c c 2$ central domain chromatin (Fig. 2C, bottom). A noticeably higher level of Hap2-GFP was consistently detected across ectopic ura4:cc2 central domain DNA assembled in $\mathrm{H} 3$ chromatin relative to the same DNA sequence at the native cen2 central domain assembled in CENP-A ${ }^{\text {Cnp } 1}$ chromatin (Fig. 2D). Loss of Hap2 does not affect the association of Ino80-HA with these regions (Supplemental Fig. S2B), while Hap2 chromatin association is lost in the absence of Ies 4 but remains unaffected in iec1 $1 \Delta$, ies $2 \Delta$ and arp $5 \Delta$ cells (Fig. 2E; Supplemental Fig. S2C,D). In budding yeast, different subunits of Ino80 have been shown to have broad interactions around NFRs and +1 nucleosomes (Yen et al. 2013). As Hap2 is a subunit of Ino80C, we examined genome-wide localization of Hap2 and Arp5. High coincidence was observed for Hap2 and Arp5 peaks (Fig. 2F). We conclude that the Ino80C subunit Hap2 is a nuclear protein that associates with noncentromeric loci and is preferentially recruited to centromeric central domain chromatin when assembled in $\mathrm{H} 3$ rather than CENP$\mathrm{A}^{\mathrm{Cnp} 1}$ chromatin. Hap2 chromatin association is dependent on the Ino80C subunit Ies4, and Hap2 colocalizes genome-wide with the Arp5 canonical Ino80C subunit.

\section{Hap2 is required to maintain CENP-A ${ }^{\text {Cnp1 }}$ chromatin across endogenous centromeres}

Cells lacking Hap2 exhibit an elevated frequency of lagging chromosomes during mitosis, indicating that loss of 
A

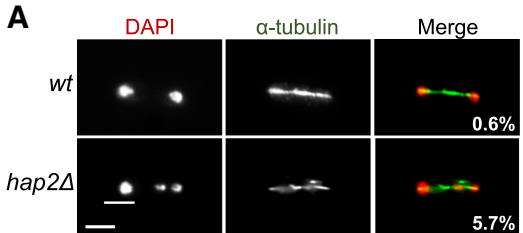

C

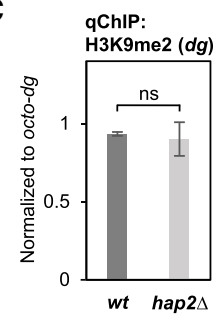

D $\quad$ QRT-PCR

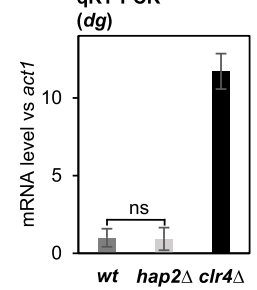

$\mathbf{F}$

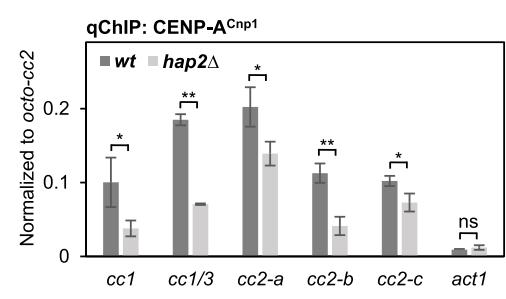

B
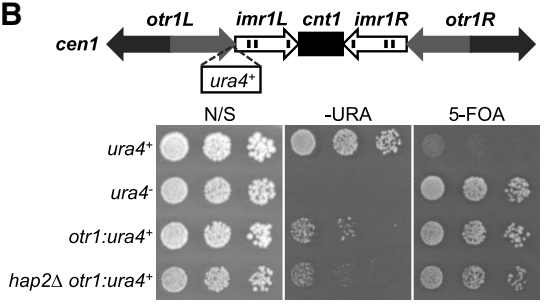

E
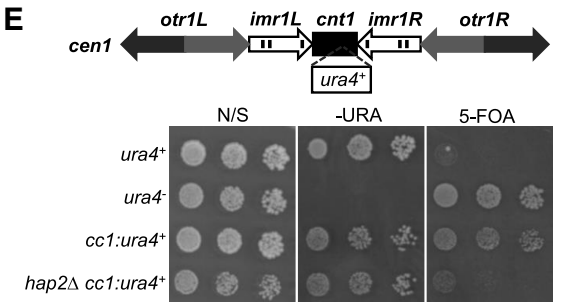

G

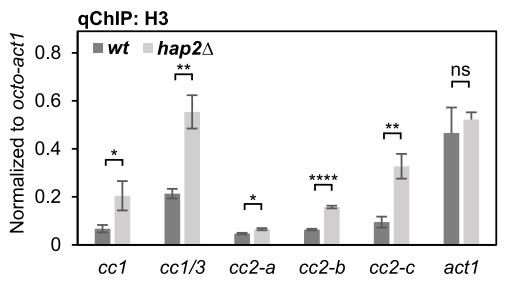

Figure 3. Hap2 is required to maintain CENP-A ${ }^{\text {Cnpl } 1}$ chromatin but not the adjacent pericentric heterochromatin. (A) Frequency of lagging chromosomes in anaphase cells. Representative images of wild-type and hap2 $\Delta$ cells stained with DAPI (red) and antitubulin (green). Percentage of late anaphase cells (wild type: $n=487$ and hap2 $\Delta: n$ =492) displaying lagging chromosomes is indicated. Scale bar, $5 \mu \mathrm{m}$. $(B, t o p)$ Diagram indicating position otr1:ura $4^{+}$marker gene inserted in outer repeat heterochromatin of cen1. (Bottom) Growth assay for central domain silencing at otr1:ura $4^{+}$. Fivefold serial dilution of cell cultures were spotted on nonselective (N/S), selective (-URA), or counter-selective (FOA) plates. $(C)$ qChIP for $\mathrm{H} 3 \mathrm{~K} 9 \mathrm{me} 2$ at outer repeat heterochromatin $(d g)$. Error bars indicate mean $\pm \operatorname{SD}(n=3)$. $(D)$ qRT-PCR of pericentric $d g$ repeats performed on total RNA extracted from indicated strains. Transcript levels are shown relative to $a c t 1^{+}$and normalized to wild type $(n=3)$. $(E$, top $)$ Diagram indicating position $c c 1$ :ura $4^{+}$marker gene within the central CENP-A ${ }^{\text {Cnp1 }}$ domain cen1 (cnt1) relative to the outer repeat (otr) and innermost repeats (imr). (Bottom) Growth assay

for central domain silencing at cen1:ura $4^{+}$as in $B .(F, G)$ qChIP for CENP-A ${ }^{\mathrm{Cnp} 1}(F)$ and histone $\mathrm{H} 3(G)$ at five locations within endogenous centromeres $(c c 1, c c 1 / 3, c c 2-a, c c 2-b$, and $c c 2-c)$ and noncentromere locus $\left(a c t 1^{+}\right)$. Error bars indicate mean $\pm \operatorname{SD}(n=3)$. Significance of the differences observed between wild-type and hap2 $\Delta$ was evaluated using Student's $t$-test in $C, D, F$, and $G$. $\left({ }^{*}\right) P<0.05 ;\left(^{* *}\right) P<0.005 ;\left(^{* * * *}\right) P<$ 0.00005 ; (n.s.) not significant.

Hap2 may affect centromere function (Fig. 3A). Defective centromere function can result from reduced pericentromeric heterochromatin formation on $d g / d h$ outer repeats or CENP-A ${ }^{\text {Cnp1 }}$ chromatin/kinetochore assembly and these can be sensitively detected by the use of silent $\mathrm{ura}^{+}$reporter genes inserted within outer repeat hetero-

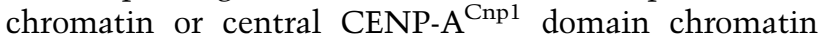
(Allshire et al. 1994, 1995; Partridge et al. 2000). No alleviation of heterochromatin-mediated silencing at otr1: $\mathrm{ura}^{+}$was detected in hap $2 \Delta$ cells relative to wild type as indicated by similar poor growth on selective plates lacking uracil (-URA) and good growth on counter-selective 5-FOA plates (Fig. 3B; Supplemental Fig. S3A). Consistent with this observation, no significant change was detected in the levels of the heterochromatin H3K9me2 mark or $d g$ transcripts produced by the underlying outer repeats in hap2s relative wild-type cells (Fig. 3C,D).

Central CENP-A ${ }^{\text {Cnp1 }}$ domain chromatin is also transcriptionally repressive (Allshire et al. 1994, 1995). Defects in CENP-A ${ }^{\text {Cnp1 }}$ chromatin assembly alleviates this transcriptional silencing (Partridge et al. 2000; Pidoux et al. 2003). To test whether loss of Hap2 affects CENP$\mathrm{A}^{\mathrm{Cnp} 1}$-mediated silencing we examined silencing of ura $^{+}$embedded in central CENP-A ${ }^{\text {Cnp1 }}$ chromatin at cen1 $\left(\right.$ cc1:ura $\left.4^{+}\right)$. Reduced silencing in hap2s cells, indicated by reduced growth on counter-selective FOA plates, suggested a defect in CENP-A ${ }^{\text {Cnp1 }}$ chromatin integrity (Fig. 3E; Supplemental Fig. S3B). qChIP analysis detected significantly lower levels of CENP-A ${ }^{\text {Cnp1 }}$ and a reciprocal increase in $\mathrm{H} 3$ levels across the central domain of centromeres in hap2s relative to wild-type cells (Fig. 3F,G), consistent with the silencing defect. Importantly, loss of Hap2 does not affect the total cellular levels of GFPCENP-A ${ }^{\text {Cnp1 }}$ or the expression of genes encoding proteins that are known to regulate CENP-A ${ }^{\text {Cnp1 }}$ loading at centromeres (Supplemental Fig. S3C,D). We conclude that loss of Hap2 specifically affects silencing through loss of CENP-A ${ }^{\text {Cnp1 }}$ and gain of $\mathrm{H} 3$ within the central domain of centromeres, thus Hap2 is required to maintain CENP$\mathrm{A}^{\mathrm{Cnp} 1}$ chromatin integrity at endogenous centromeres.

\section{Hap2 is required for the de novo establishment of CENP-A $A^{\text {Cnp } 1}$ chromatin}

Many factors are known to assist CENP-A maintenance but little is known about the factors required for the de novo establishment of CENP-A chromatin. De novo establishment of functional centromeres can occur following the introduction of naked centromere DNA into cells (Catania et al. 2015). We first examined whether Hap 2 and other subunits of Ino80C are required for the de novo establishment of centromeres on the $\mathrm{pHcc} 2 \mathrm{mini}$ chromosome (Fig. 4A). hap2s cells exhibited a complete failure to establish functional centromeres, similar to clr4 $\Delta$ cells that lack heterochromatin, while ies $2 \Delta$ displayed increased establishment, iec1 $\Delta$ and ies $4 \Delta$ were less competent in establishing functional centromeres on pHcc2 (Fig. 4B; Supplemental Fig. S4A). In S. pombe, 
A
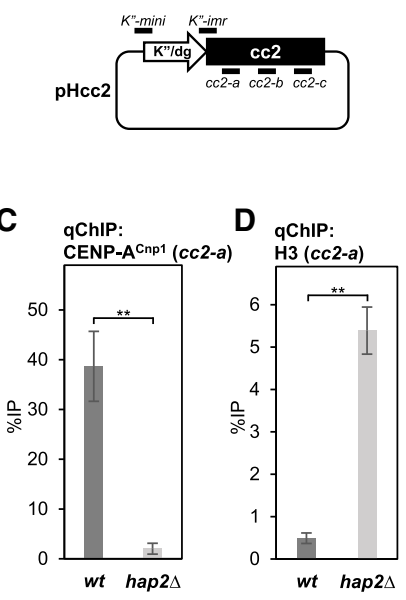

B
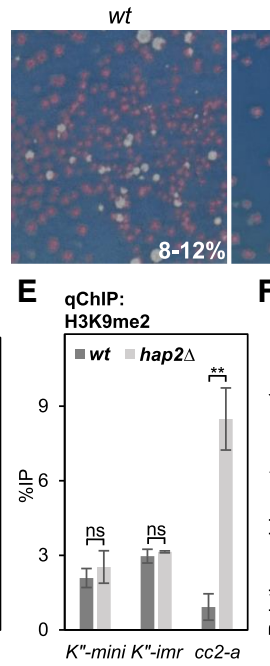

$c \mid r 4 \Delta$

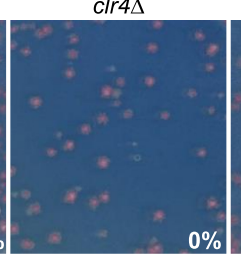

F

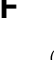

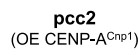
$0 \%$
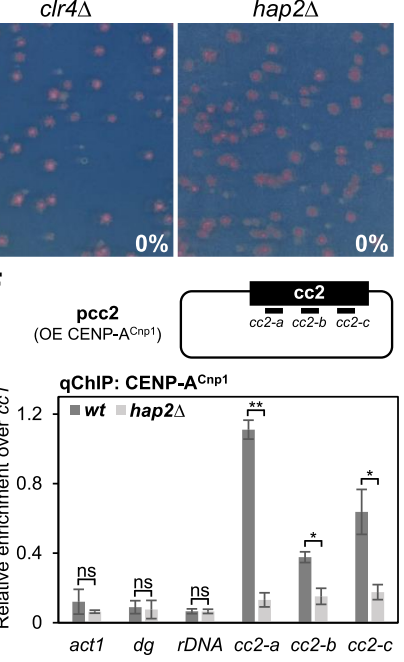

Figure 4. Hap2 is required for the de novo establishment of CENP-A ${ }^{\text {Cnpl }}$ chromatin. $(A)$ Schematic representation of pHcc2 minichromosome $\mathrm{K}^{\prime \prime} / \mathrm{dg}$ repeat adjacent to central domain 2 DNA. Position of the primer pair at the edge of $\mathrm{K}^{\prime \prime} / \mathrm{dg}$ repeat and within central domain 2 DNA are indicated. $(B)$ Transformants containing pHcc2 minichromosome plasmids were replica-plated to low adenine nonselective plate. Representative plate showing colony color and centromere establishment frequency in wild type $(n=515)$, hap2 $\Delta(n=390)$, and strains lacking heterochromatin $c l r 4 \Delta(n=$ 870). $(C, D)$ qChIP for CENP-A ${ }^{\text {Cnpl }}$ and histone $\mathrm{H} 3$ at plasmid-borne central domain 2 DNA (cc2-a) on pHcc2 minichromosome. Error bars indicate mean $\pm \mathrm{SD}(n=3)$. (E) qChIP for $\mathrm{H} 3 \mathrm{~K} 9 \mathrm{me} 2$ at plasmid-borne $\mathrm{K}^{\prime \prime} / \mathrm{dg}$ repeat $\left(K^{\prime \prime}\right.$ mini and $K^{\prime \prime}$-imr) and plasmid-borne central domain 2 DNA $(c c 2-a)$ on pHcc2 minichromosome. Error bars indicate mean $\pm \mathrm{SD}(n=3) .(F$, top) Schematic representation of pcc2 minichromosome without $\mathrm{K}^{\prime \prime} / \mathrm{dg}$ repeat transformed in cells overexpressing CENP-A ${ }^{\text {Cnp } 1}$. (OE) Overexpression. (Bottom) qChIP for CENP-A ${ }^{\mathrm{Cnp} 1}$ at noncentromere locus $\left(\right.$ act $\left.1^{+}\right)$, outer repeat heterochromatin $(d g)$ and ribosomal DNA $(r D N A)$, and three locations within plasmid-borne central core 2 DNA $(c c 2-a, c c 2-b$, and $c c 2-c)$ on pcc2 minichromosome relative to CENP-A ${ }^{\text {Cnp1 }}$ levels at endogenous centromeres $(c c 1 / 3)$. Error bars indicate mean \pm SD $(n=3)$. Significance of the differences observed between wild type and hap2 $\Delta$ was evaluated using Student's $t$-test in $\left.C-F .{ }^{*}\right) P<0.05$; $\left(^{* *}\right) P<0.005$; (n.s.) not significant.

de novo CENP-A ${ }^{\text {Cnp1 }}$ chromatin establishment on circular plasmid-based minichromosomes requires a block of heterochromatin in close proximity to central domain DNA (Folco et al. 2008; Kagansky et al. 2009). Loss of centromere establishment could result from a failure to establish CENP-A ${ }^{\mathrm{Cnp} 1}$ chromatin, and/or adjacent heterochromatin, on the minichromosome. To distinguish between these possibilities, CENP-A ${ }^{\text {Cnp1 }}$ levels on the plasmid-borne central domain cc2 DNA were analysed. All strains used have $6 \mathrm{~kb}$ of cen 2 central domain DNA replaced with $5.5 \mathrm{~kb}$ of cen 1 central domain DNA at endogenous centromeres $(c c 2 \Delta:: c c 1)$ so that the plasmid-borne cc2 is the only copy of this element. qChIP revealed that CENP-A ${ }^{\text {Cnp1 }}$ was not assembled over cc2 carried by pHcc2 in hap2 $\Delta$ cells (Fig. 4C). Reciprocally, a high level of $\mathrm{H} 3$ was detected across cc2 of pHcc2 in the absence of CENP-A ${ }^{\text {Cnp1 }}$ assembly in hap2 2 cells (Fig. 4D). qChIP for H3K9me2 demonstrated that loss of Hap2 did not affect the establishment of heterochromatin on the plasmid-borne $\mathrm{K}^{\prime \prime} / \mathrm{dg}$ repeat (Fig. 4E). Interestingly, high levels of $\mathrm{H} 3 \mathrm{~K} 9 \mathrm{me} 2$ were detected within the central domain of the pHcc2 minichromosome in hap2s but not wild-type cells (Fig. 4E). This suggests that in the absence of CENP-A ${ }^{\text {Cnp1 }}$ chromatin establishment in hap2s cells heterochromatin may spread from the outer $\mathrm{K}^{\prime \prime} / \mathrm{dg}$ repeat into the plasmid-borne central cc2 domain. To test whether Hap2 is required for the de novo establishment of CENP-A ${ }^{\text {Cnp1 }}$ chromatin independently from the requirement for adjacent heterochromatin, the plasmid pcc2 which carries $8.5 \mathrm{~kb}$ of cen2 central domain DNA, but no heterochromatin forming outer repeat sequences, was transformed into cells expressing additional GFP-

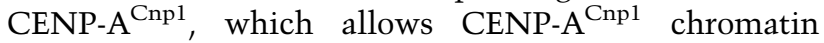
assembly (Fig. 4F, top; Catania et al. 2015). In contrast to wild type, hap2 $\triangle$ cells did not assemble high levels of CENP-A ${ }^{\text {Cnp1 }}$ over the central domain of the pcc2 minichromosome (Fig. 4F, bottom). This effect was not due to altered CENP-A ${ }^{\text {Cnp1 } 1}$ protein levels in hap2 2 compared with wild-type cells (Supplemental Fig. S4B). We conclude that Hap2 is critical for the de novo establishment of CENP-A ${ }^{\text {Cnp } 1}$ chromatin on naïve central domain centromere DNA.

\section{Hap2 promotes histone turnover in genomic regions prone to CENP-A ${ }^{\text {Cnp1 }}$ assembly}

Central domain DNA inserted at a noncentromeric location on the arm of a chromosome, such as the ura4 locus on chromosome 3 (ura4:cc2), remains assembled in H3 nucleosomes and exhibits a high rate of histone $\mathrm{H} 3$ turnover (Shukla et al. 2018). The inherent instability of H3 nucleosomes assembled on this ectopic ura4:cc2 centromere DNA has been proposed to aid the incorporation of CENP-A ${ }^{\text {Cnp1 }}$ when available (Shukla et al. 2018). In S. cerevisiae, Ino80 associates with promoter-associated nucleosome-depleted regions and transcription start sites (TSS) where it mediates the turnover of +1 nucleosomes (Yen et al. 2013). The requirement for Hap2 in de novo CENP-A $^{\text {Cnp1 }}$ assembly on central domain DNA may result from defective $\mathrm{H} 3$ nucleosome turnover on these centromeric sequences when assembled in $\mathrm{H} 3$ chromatin alone. We therefore used recombination-induced tag exchange (RITE) (Verzijlbergen et al. 2010; Shukla et al. 2018) to measure replication-independent H3 turnover in G2-arrested wild-type and hap2s cells on ectopic ura4:cc2, heterochromatic repeats, and highly transcribed genes. This H3.2-HA $\rightarrow \mathrm{T} 7$ tag swap was induced in $c d c 25-$ 22/G2-arrested cells and the incorporation of new histone 
Singh et al.

A
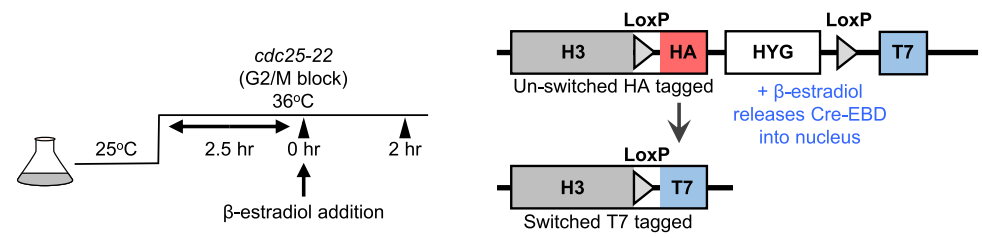

B qChIP: New H3-T7/Total H3

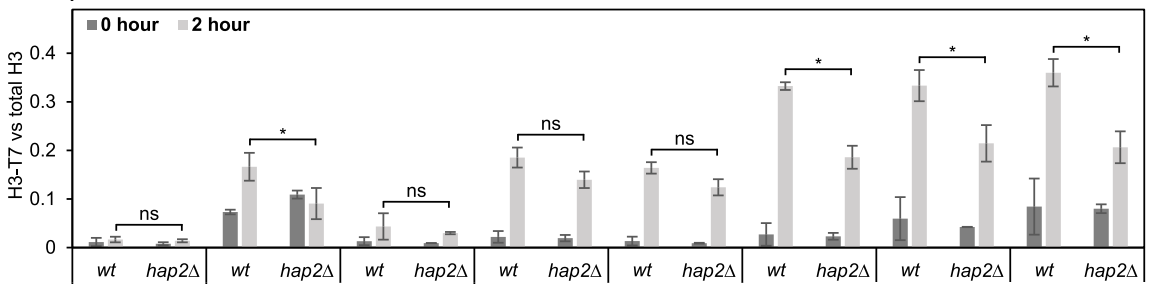

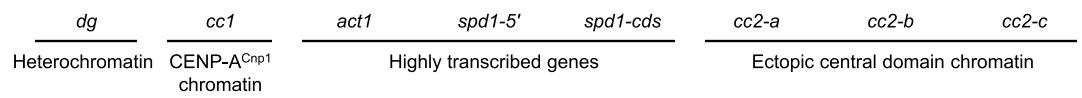

C Non-centromeric CENP-A ${ }^{\text {Cnp1 islands }}$

\begin{tabular}{|l|l|l|c|}
\hline Chromosome & Start & End & Length(bp) \\
\hline Chrl : NCIS1 & 3710401 & 3710900 & 499 \\
\hline Chrl & 3711001 & 3711350 & 349 \\
\hline Chrl & 3723451 & 3723650 & 199 \\
\hline Chrl & 3745201 & 3745700 & 499 \\
\hline Chrl & 3751801 & 3752150 & 349 \\
\hline Chrl & 3795451 & 3795800 & 349 \\
\hline Chrl : NCIS2 & 3844351 & 3844550 & 199 \\
\hline Chrl & 3897151 & 3897350 & 199 \\
\hline Chrll & 1598551 & 1598900 & 349 \\
\hline Chrll & 1650601 & 1650800 & 199 \\
\hline Chrll : NC/S3 & 1684501 & 1684700 & 199 \\
\hline Chrlll & 814801 & 815000 & 199 \\
\hline Chrlll & 1065001 & 1065950 & 949 \\
\hline Chrlll : NC/S4 & 1211551 & 1211750 & 199 \\
\hline
\end{tabular}

D ChrI

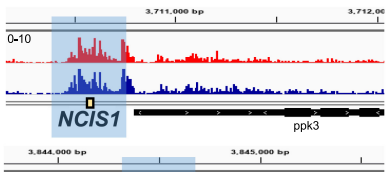

ChrI
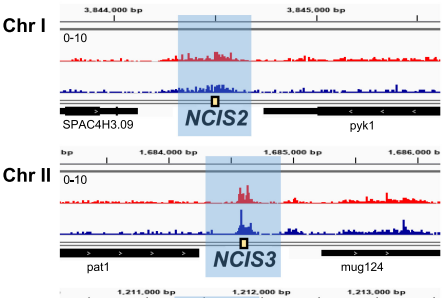

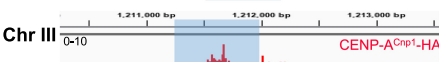

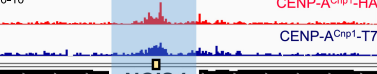

E
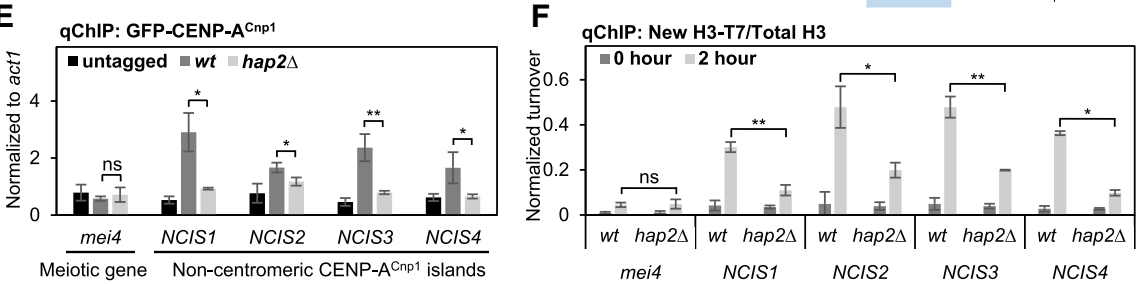

Figure 5. Hap2 is required for high histone $\mathrm{H} 3$ turnover on central domain centromere DNA and islands of noncentromeric CENP-A incorporation. (A) Experimental setup to assess replication-independent H3 turnover. The cdc25-22 temperature sensitive mutation was used to block wild-type and hap2 $\Delta$ cells in G2, the HA tag on H3 was swapped for the T7 tag by $\beta$-estradiol induced Cre/loxP mediated recombination. Samples were collected at 0 and $2 \mathrm{hr}$ and analyzed by qChIP. (B) qChIP analysis of new H3.2-T7 incorporated in $c d c 25-22 /$ G2-arrested cells at pericentromeric outer repeat heterochromatin $(d g)$, the central CENP-A ${ }^{\text {Cnp1 }}$ domain of cen1 (cc1), highly transcribed genes $\left(a c t 1^{+}\right.$and $\left.s p d 1^{+}\right)$and three locations within ectopically located ura4:cc2 lacking CENP-A ${ }^{\text {Cnpl }}(c c 2-a, c c 2-b$, and $c c 2-c)$. (Y-axis) H3.2-T7\% IP values normalized to the respective total H3\%IP values represent normalized turnover for each sample. Error bars indicate mean $\pm \mathrm{SD}(n=3)$. $(C)$ ChIP-nexus analysis of HA and T7 tagged CENP-A ${ }^{\text {Cnp1 }}$ reveals consistent noncentromeric CENP-A ${ }^{\text {Cnp1 }}$ islands (NCIS) of incorporation above background at 14 locations in the genome. $(D)$ Four CENP-A ${ }^{\text {Cnp1 }}$ islands are shown: NCIS1, NCIS2, NCIS3, and NCIS4. (E) qChIP for GFP-CENP-A ${ }^{\text {Cnp1 }}$ at noncentromeric CENP-A ${ }^{\text {Cnp1 }}$ islands using indicated primer pairs (yellow boxes in $D)$ and meiotic-specific gene $\left(\right.$ meit $\left.^{+}\right)$. Error bars indicate mean $\pm \mathrm{SD}(n=3)$. $(F)$ qChIP analysis of new H3.2-T7 incorporation in cdc25-22/G2-arrested cells at NCIS1, NCIS2, NCIS3, and NCIS4. Error bars indicate mean \pm SD $(n=3)$. Error bars indicate mean \pm SD $(n=3)$. Significance of the differences observed between wild type and hap2 $\Delta$ was evaluated using Student's $t$-test in $B, E$, and $F$. $\left({ }^{*}\right) P<$ $0.05 ;\left({ }^{* *}\right) P<0.005 ;$ (n.s.) not significant.

H3.2-T7 was monitored (Fig. 5A). Importantly, the H3.2$\mathrm{HA} \rightarrow \mathrm{T} 7$ tag swap efficiency was unaffected by hap $2 \Delta$ relative to wild-type cells (Supplemental Fig. S5A). Compared with wild-type cells, a significant decrease in the level of H3 turnover was evident on ectopic ura4:cc2 centromere DNA in hap2s cells (Fig. 5B). Similarly, H3 turnover within endogenous cen1-cc1 assembled in CENP-A ${ }^{\text {Cnp1 }}$ chromatin was also reduced in hap2s cells. In contrast, H3 turnover remained unchanged within heterochromatic outer repeats $(d g)$ and over highly 
transcribed genes $\left(a c t 1^{+}\right.$and $\left.s p d 1^{+}\right)$. Ino80 may mediate nucleosome turnover through eviction of H2A.Z (Papamichos-Chronakis et al. 2011). However, the levels of H2A. $Z^{\text {Pht1 }}$ associated with endogenous $c c 1$ and ectopic ura4:cc2 were unaffected by loss of Hap2 (Supplemental Fig. S5B). We conclude that Hap2 is required to ensure H3 nucleosome instability on centromeric sequences by mediating a high frequency of $\mathrm{H} 3$ turnover, which may consequently allow the incorporation of CENP-A ${ }^{\text {Cnp1 }}$ in place of $\mathrm{H} 3$.

Overexpression of CENP-A ${ }^{\text {Cnp1 }}$ results in low levels of

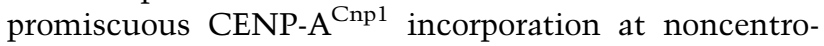
meric locations (Choi et al. 2012; Castillo et al. 2013). Fission yeast CENP-A ${ }^{\text {Cnp1 }}$ expression is known to increase prior to that of canonical histones in advance of replication. Consequently, even without overexpression, in early $S$ phase this natural excess of CENP-A ${ }^{\text {Cnp1 }}$ results in low levels of newly synthesized CENP-A ${ }^{\text {Cnp1 }}$ being incorporated across many gene bodies (Shukla et al. 2018). ChIP-Nexus (a modified exo-ChIP-seq protocol) (He et al. 2015) analysis allowed detection of noncentromeric genomic regions where islands of CENP-A ${ }^{\text {Cnp1 }}$ are retained at low levels (Fig. 5C,D). Hap2-GFP was found to associate with these noncentromeric CENP-A ${ }^{\text {Cnp1 }}$ islands (NCIS), while loss of Hap2 significantly decreased CENP$\mathrm{A}^{\mathrm{Cnp} 1}$ incorporation within these islands (Fig. 5E). Consistent with previous results, Hap2 association with NCIS requires Ies4, but not Iec1, Ies2, or Arp5 (Supplemental Fig. S5C,D). Interestingly, qChIP also revealed reduced histone $\mathrm{H} 3$ turnover within these noncentromeric CENP-A ${ }^{\text {Cnp } 1}$ islands in hap2 $\Delta$ cells, whereas histone H3 turnover remained unchanged within the heterochromatic outer repeats, the $a c t 1^{+}$gene, or the repressed meiosisspecific mei4 $^{+}$gene (Fig. 5F). We conclude that Hap2 also promotes a high rate of $\mathrm{H} 3$ turnover at several noncentromeric NCIS loci prone to low-level CENP-A ${ }^{\text {Cnp1 incorpo- }}$ ration. This observation reinforces the involvement of Hap2-Ino80C in mediating histone $\mathrm{H} 3$ turnover and the exchange of histone $\mathrm{H} 3$ for CENP-A ${ }^{\mathrm{Cnp} 1}$-containing nucleosomes.

\section{Hap2 facilitates transcription of central domain chromatin}

The central CENP-A ${ }^{\text {Cnp1 }}$ domain of $S$. pombe centromeres is transcribed from many TSS and the resulting RNAs are short-lived (Choi et al. 2011; Sadeghi et al. 2014; Catania et al. 2015). Transcription can provide the opportunity for histone exchange/remodeling of resident nucleosomes (Venkatesh and Workman 2015). It is therefore feasible that transcription-coupled processes also promote the exchange of $\mathrm{H} 3$ for CENP-A ${ }^{\text {Cnp1 }}$ in chromatin assembled on centromere DNA. Relatively high levels of RNAPII are detected on central domain DNA when assembled in $\mathrm{H} 3$ chromatin at ectopic ura4:cc2 or on the pcc2 minichromosome, yet only low levels of RNAPII are detectable within endogenous centromeric central domain CENP-A ${ }^{\text {Cnp1 }}$ chromatin (Catania et al. 2015; Shukla et al. 2018). Since CENP-A ${ }^{\text {Cnp1 }}$ is primarily deposited during G2, we investigated whether Hap2 affects transcription from ectopic ura4:cc2 in mid-G2 cells from cdc25-22 synchronized cultures (Fig. 6A). qChIP was used to measure the levels of total RNAPII, initiating RNAPIIS5P and elongating RNAPIIS2P levels across ura4:cc2. RNAPIIS5P levels were significantly lower across this ectopic central domain DNA in hap2 $\Delta$ compared with wild-type cells, but no obvious difference was detected within the CENP-A ${ }^{\mathrm{Cnp} 1}$ chromatin regions of endogenous centromeres (Fig. 6B). These data suggest that Hap2 promotes efficient transcriptional initiation from central domain DNA assembled in $\mathrm{H} 3$ chromatin (ura4:cc2). In contrast, the levels of total and elongating RNAPIIS2P associated with ectopic central domain DNA remained unchanged in hap $2 \Delta$ relative to wild-
A
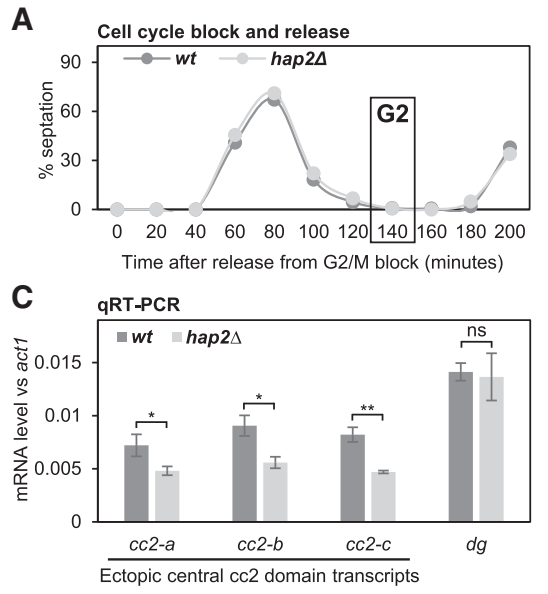

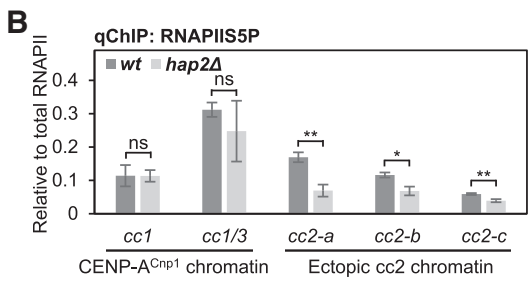

D

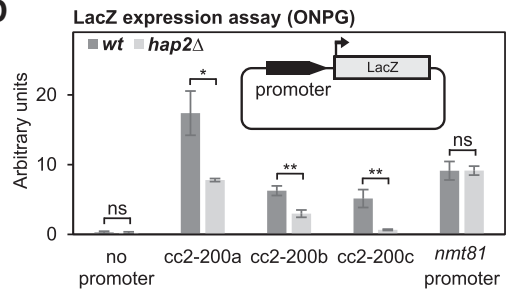

Figure 6. Transcription from centromeric DNA is reduced in the absence of Hap2. $(A)$ cdc25-22 synchronized cell populations were used to assess levels of RNAPIIS5P and central core transcripts during $\mathrm{G} 2$ in $B$ and $C$. The septation index for wild type and hap2 $\Delta$ were measured and cells were collected in G2 (T-140). (B) qChIP for initiating RNAPIIS5P at two locations within endogenous centromeres $(c c 1$ and $c c 1 / 3)$ and three locations within ectopically located ura4:cc2 lacking CENP-A ${ }^{\mathrm{Cnp} 1}(c c 2-a, c c 2$ $b$, and $c c 2-c)$ in wild type and hap2 $\Delta$. Error bars indicate mean $\pm \mathrm{SD}(n=3)$. (C) qRT-PCR to quantify transcripts from three locations within ectopically located ura4:cc2 lacking CENP$\mathrm{A}^{\mathrm{Cnp} 1}(c c 2-a, c c 2-b$, and $c c 2-c)$ and from pericentromeric outer repeat $(d g)$ on total RNA extracted from wild-type and hap $2 \Delta$ cells. Transcript levels are shown relative to $a c t 1^{+}$. Error bars indicate mean $\pm \mathrm{SD}(n=3)$. $(D)$ Measurement of LacZ expression driven by three 200-bp $c c 2$ fragments with promoter activity (cc2-200a, cc2-200b, and cc2-200c), the $n m t 81$ promoter, and no promoter following transformation of plasmids into wild type and hap2 $\Delta$ using the ONPG substrate/absorbance at $420 \mathrm{~nm}$. Error bars indicate mean $\pm \operatorname{SD}(n=3)$. (Inset) Diagram of plasmids with different 200-bp fragments from central domain region of cen2 (cc2) placed upstream of the LacZ reporter. Significance of the differences observed between wild type and hap $2 \Delta$ was evaluated using Student's $t$-test in $B-D .\left({ }^{*}\right) P<0.05$; $\left(^{* *}\right) P<0.005$; (n.s.) not significant. 
type cells (Supplemental Fig. S6A,B). Consistent with reduced transcriptional initiation, lower levels of central domain transcripts were produced from ectopic ura4:cc2 in hap $2 \Delta$ cells (Fig. 6C). Transcript levels from outer repeats and $a c t 1^{+}$were unaffected. Thus, Hap2 is required for efficient transcriptional initiation and transcript production from ectopic central domain DNA assembled in $\mathrm{H} 3$ chromatin. The fact that no decrease in elongating RNAPIIS2P was detected across this ectopic central domain in hap $2 \Delta$ cells suggests that RNAPII remains associated with the central domain template for longer when Hap2 is absent.

Regions upstream of TSS within the central domain of cen2 exhibit promoter activity (Catania et al. 2015). To determine whether Hap2 affects the transcription from these central domain promoters, the production of $\beta$-galactosidase was assessed when 200-bp promoter-containing cc2 fragments were placed upstream of lacZ (Fig. 6D, inset). Three central domain promoters exhibited significantly lower promoter activity in hap $2 \Delta$ compared with wild-type cells, whereas the control nmt81 promoter was unaffected (Fig. 6D; Supplemental Fig. S6C,D). We conclude that Hap2 is required for efficient transcription from central domain promoters and that this facilitates transcription-coupled histone exchange, thereby providing an opportunity for replacement of $\mathrm{H} 3$ with CENP$\mathrm{A}^{\mathrm{Cnp} 1}$ to establish CENP-A ${ }^{\mathrm{Cnp} 1}$ chromatin domains and assemble functional kinetochores.

\section{Discussion}

The mechanisms that contribute to the maintenance, and especially the establishment, of CENP-A chromatin remain poorly understood. To gain insight into how CENP-A chromatin is established on naïve centromere DNA, we applied proteomics to identify proteins associated with fission yeast CENP-A ${ }^{\text {Cnp1 }}$ chromatin. In addition to kinetochore proteins, all Ino80C subunits, including the small auxiliary subunit, Hap2, were found to be significantly enriched in solubilized CENP-A ${ }^{\text {Cnp1 }}$ chromatin. Hap2 and the Arp5 Ino80C subunit exhibit similar chromosomal distributions and Hap2 chromatin association depends on the Ies4 Ino80C subunit. Hap2 was found to promote CENP-A ${ }^{\mathrm{Cnp} 1}$ chromatin integrity at centromeres and to be required for the de novo establishment of CENP$\mathrm{A}^{\mathrm{Cnp} 1}$ chromatin on introduced naïve centromere DNA. The requirement for Hap2 in ensuring high histone $\mathrm{H} 3$ turnover on endogenous centromere DNA, ectopically located centromere DNA, and noncentromeric CENP$\mathrm{A}^{\mathrm{Cnp} 1}$ islands indicates that Hap2-Ino80C drives H3 nucleosome turnover at these locations. The loss of CENP$\mathrm{A}^{\mathrm{Cnp} 1}$ incorporation from NCIS islands in the absence of Hap2 underscores the role for Hap2-Ino80C-mediated

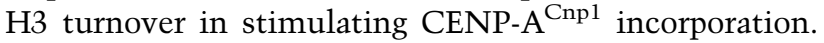
Strikingly, Hap2 is required for efficient transcription specifically from central domain promoters. We propose a mechanism in which Hap2-Ino80C drives the inherent instability of $\mathrm{H} 3$ nucleosomes on centromeric DNA via transcription-coupled nucleosome turnover, providing
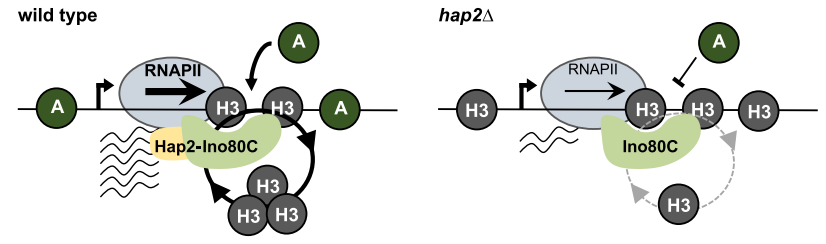

Figure 7. Hap2-Ino80-mediated transcription facilitates de novo establishment of CENP-A ${ }^{\text {Cnp } 1}$ chromatin. Model for the establishment of CENP-A ${ }^{\text {Cnp1 }}$ chromatin in S. pombe. (Left) Hap2 is required for transcription initiation events to maintain high $\mathrm{H} 3$ turnover thus renders $\mathrm{H} 3$ nucleosomes unstable on centromeric sequences allowing its replacement with CENP-A ${ }^{\text {Cnpl }}$ nucleosomes. (Right) Cells lacking Hap2 have lower transcription initiation events that stabilize the $\mathrm{H} 3$ nucleosomes on centromeric sequences thus lowering its propensity to establish CENP$\mathrm{A}^{\text {Cnp1 }}$ chromatin.

the opportunity for incorporation of CENP-A ${ }^{\text {Cnp1 }}$ in place of histone H3, when CENP-A ${ }^{\text {Cnp1 }}$ is available (Fig. 7).

Studies in a variety of species have shown that Ino80C influences transcription (Cai et al. 2007; Klopf et al. 2009; Hogan et al. 2010). The noncanonical human Yin Yang 1 (YY1) transcription factor is known to associate with Ino80 and facilitate both transcriptional activation and repression (Yao et al. 2001; Cai et al. 2007). It is also known that Ino80 suppresses antisense and other noncoding transcription (Alcid and Tsukiyama 2014; Marquardt et al. 2014). The noncoding transcription of centromeric DNA by RNAPII has been implicated in CENP-A deposition in several systems (Chueh et al. 2009; Chan et al. 2012; Rošić et al. 2014; Grenfell et al. 2016; McNulty et al. 2017). However, both reduced and increased transcription of centromere DNA appears to be incompatible with CENP-A chromatin integrity and centromere function (Hill and Bloom 1987; Nakano et al. 2008; Ohkuni and Kitagawa 2011; Bergmann et al. 2012). Such observations suggest that an appropriate level and type of programmed transcription may be required to promote CENP-A assembly on centromere DNA.

Each fission yeast centromere contains a central domain of $\sim 10 \mathrm{~kb}$ assembled in CENP-A ${ }^{\mathrm{Cnp} 1}$ rather than H3 nucleosomes. Multiple transcriptional start sites are detected on both strands when central domain is assembled in $\mathrm{H} 3$, rather than CENP-A $\mathrm{A}^{\mathrm{Cnp} 1}$, chromatin at an ectopic locus (Choi et al. 2011; Catania et al. 2015), indicating that these regions are pervasively transcribed. Distinct Ino80C modules undertake particular tasks such as nucleosome binding, sliding, and ATPase activity (Chen et al. 2011). The specific impact of Hap2 on Ino80C activity and how this is altered by loss of other subunits such as Ies 4 remains to be determined. However, a major activity of Ino80C is to slide nucleosomes relative to sizable lengths of flanking unoccupied DNA (Udugama et al. 2011). Thus, the generation of nucleosome free regions that facilitate RNAPII recruitment, and consequently transcription, are an intrinsic facet of Ino80C function. Consequently, the loss of Hap2-Ino80C is expected to occlude central domain promoters with nucleosomes and result in reduced transcriptional initiation. 
Since RNAPII recruitment to central domain chromatin during G2 phase of the cell cycle is coincident

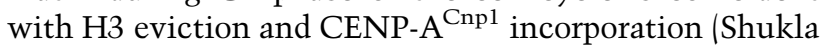
et al. 2018), it is likely that these events are somehow coupled. The conserved heptad repeat composing the C-terminal domain (CTD) of RNAPII undergoes S5 phosphorylation (S5P) at promoters upon transcription initiation and $\mathrm{S} 2$ phosphorylation $(\mathrm{S} 2 \mathrm{P})$ in coding regions during transcriptional elongation (Komarnitsky et al. 2000). RNAPII stalls when it encounters obstacles such as DNA damage or natural barriers (Poli et al. 2017). Despite relatively high levels of RNAPII being detected on H3-assembled ectopic central domain, meagre levels of transcripts are produced, consistent with transcriptional stalling (Choi et al. 2011; Catania et al. 2015). Analyses in $S$. cerevisiae show that Ino80 is required to release stalled RNAPII from chromatin and enable its proteasomal degradation (Lafon et al. 2015). Previously, we showed that mutants $\left(u b p 3 \Delta, t f_{S} 1 \Delta\right)$ expected to increase the levels of stalled RNAPIIS2P on central domain chromatin, promote CENP-A incorporation (Catania et al. 2015). Interestingly, cells lacking Hap2 display lower initiating RNAPIIS5P over ectopic H3-assembled central domain chromatin in G2 but the levels of total RNAPII and elongating RNAPII-S2P are unaltered (Fig. 6B; Supplemental Fig. S6A,B). This indicates that, although lower levels of initiation and transcription take place within ectopic central domain chromatin in the absence of Hap2, elongating RNAPII is retained across the domain. We interpret these observations to indicate that Hap2-Ino80C is required to release elongating RNAPII that becomes trapped or stalled in central domain chromatin. We suggest that resident $\mathrm{H} 3$ nucleosomes are evicted by Hap2-Ino80C as part of the process involved in removing this stalled RNAPII. Thus, centromere DNA may be programmed to be pervasively transcribed and stall RNAPII over a relatively large $10-\mathrm{kb}$ region in order to recruit Hap2-Ino80C and trigger $\mathrm{H} 3$ turnover throughout this extensive domain, thereby providing the opportunity for CENP-A incorporation. Stalling may result from collisions between converging RNAPII complexes or other obstacles such as the replication origin recognition complex (ORC) which is bound to the many AT-rich tracts present within central domain regions (Hayashi et al. 2007). Alternatively, elongating RNAPII on central domain DNA may be somehow earmarked for removal using cues analogous to those that allow Ino80 to suppresses antisense and cryptic unstable transcripts (Alcid and Tsukiyama 2014). Thus, pervasive transcription across an extensive region such as the central domain may itself provoke Ino80C recruitment.

Histone turnover rates are generally higher for nucleosomes close to promoters (Dion et al. 2007). The +1 nucleosomes exhibit high levels of turnover and Ino80C has been reported to mediate the exchange of H2A.Z for canonical H2A in such nucleosomes (Papamichos-Chronakis et al. 2011; Watanabe et al. 2013; Yen et al. 2013). However, H2A.Z turnover on transcribed genes has been shown to be not reliant on Ino80 activity (Tramantano et al. 2016). Moreover, Ino80 is also known to reduce transcription from some promoters, independently of its role in removing H2A.Z (Barbaric et al. 2007). The fact that no difference in the levels of H2A. $Z^{\text {Pht1 }}$ was detected across the ectopic central domain in hap $2 \Delta$ cells relative to wild-type (Supplemental Fig. S5B) suggests that Hap2-Ino80C does not mediate H2A. $Z^{\text {Pht1 }}$ eviction from central domain chromatin and that it must affect some other aspect of centromere promoter function, perhaps through its known nucleosome sliding activity. Thus, Ino80C may be required to slide nucleosomes away from central domain promoters so that they are efficiently transcribed and the resulting transcriptional properties of this domain mediate $\mathrm{H} 3$ nucleosome turnover.

Previously, we showed that CENP-A ${ }^{\text {Cnp1 }}$ competes with histone $\mathrm{H} 3$ for incorporation into centromeric chromatin and CENP-A $\mathrm{A}^{\mathrm{Cnp} 1}$ incorporation is promiscuous, replacing $\mathrm{H} 3$ when the opportunity arises (Castillo et al. 2007; Choi et al. 2011, 2012). Thus, high histone H3 nucleosome turnover, or low nucleosome occupancy, appears to be an underlying property of many sequences that are prone to CENP-A ${ }^{\text {Cnp1 }}$ assembly in fission yeast. As transcription appears to be widespread at centromeres in other organisms, high turnover of resident H3 nucleosomes, stimulated by Ino80C, may be a conserved attribute of centromeric DNA that stimulates CENP-A deposition.

\section{Materials and methods}

Additional methods are described in the Supplemental Material, including lists of strains (Supplemental Table S6), plasmids (Supplemental Table S7), and primers (Supplemental Table S8) used in this study.

Affinity purification mass spectrometry analysis

Native coimmunoprecipitated samples were analyzed on an Orbitrap Fusion Lumos Tribrid mass spectrometer and on a Q Exactive (both from Thermo Fisher Scientific) both coupled online to an Ultimate 3000 RSLCnano system (Dionex, Thermo Fisher Scientific). For details of the separation, mass spectrometer parameters, and data analysis, see the Supplemental Material and Supplemental Tables S3-S5. The MS proteomics data have been deposited to the ProteomeXchange Consortium via the Proteomics Identifications (PRIDE) (Vizcaíno et al. 2016) partner repository with the data set identifier PXD016602.

Establishment assays

Cells transformed with minichromosomes were plated on PMGuracil-adenine plates and incubated for $5-10 \mathrm{~d}$ at $32^{\circ} \mathrm{C}$ until medium-sized colonies had grown. Colonies were replica-plated to PMG low-adenine $(10 \mu \mathrm{g} / \mathrm{mL})$ plates to determine the frequency of establishment of centromere function. These indicator plates allow minichromosome loss (red colony) or retention (white/ pale pink colony) to be determined. In the absence of centromere establishment, minichromosomes behave as episomes that are rapidly lost. Minichromosomes occasionally integrate giving a false-positive white phenotype. To assess the frequency of such integration events and to confirm establishment of centromere segregation function, colonies giving the white/pale-pink phenotype upon replica plating were restreaked to single colonies on 
low-adenine plates. Sectored colonies are indicative of segregation function with low levels of minichromosome loss, whereas pure white colonies are indicative of integration into endogenous chromosomes and the establishment frequency was adjusted accordingly.

\section{LacZ assays}

LacZ assays were performed as described (Guarente 1983). Plasmids containing Lac $Z$ with upstream nmt81 promoter, 200-bp sequences from centromere 2 or no promoter were used as described (Catania et al. 2015). Plasmids were transformed into wild-type and hap $2 \Delta$ strains and grown on minimal medium.

ChIP-seq and ChIP-nexus

ChIP-seq and ChIP-nexus were prepared essentially as described (Shukla et al. 2018). For details, see the Supplemental Material. The accession number of the sequencing data reported for Hap2-GFP and Arp5-3HA is GEO GSE141524 and for CENP$\mathrm{A}^{\mathrm{Cnp} 1}$ (HA and T7 tag), GEO GSE136305.

\section{Acknowledgments}

We thank members of the Allshire laboratory for advice and useful suggestions. We thank Sito Torres-Garcia for running the ChIP samples on MiniSeq system. We thank Dominik Hoelper for critical reading of the manuscript. This research was supported by award of a Darwin Trust of Edinburgh Studentship to P.P.S., a Wellcome Senior Research Fellowship (103139), and Wellcome Instrument grant (108504) to J.R.; a Wellcome Principal Research Fellow to R.C.A. (095021 and 200885); and core funding for the Wellcome Centre for Cell Biology (203149).

Author contributions: P.P.S. and R.C.A. jointly conceived the study. P.P.S., M.S., and S.A.W. performed experiments. P.P.S., M.L., and P.T. analyzed data. T.A. provided guidance in sample preparation for mass spectrometry. C.S. and J.R. performed mass spectrometry and MaxQuant analysis. P.P.S., A.L.P., and R.C.A. wrote the manuscript with input from other authors.

\section{References}

Alcid EA, Tsukiyama T. 2014. ATP-dependent chromatin remodeling shapes the long noncoding RNA landscape. Genes Dev 28: 2348-2360. doi:10.1101/gad.250902.114

Allshire RC, Javerzat JP, Redhead NJ, Cranston G. 1994. Position effect variegation at fission yeast centromeres. Cell 76: 157169. doi:10.1016/0092-8674(94)90180-5

Allshire RC, Nimmo ER, Ekwall K, Javerzat JP, Cranston G. 1995. Mutations derepressing silent centromeric domains in fission yeast disrupt chromosome segregation. Genes Dev 9: 218233. doi:10.1101/gad.9.2.218

Barbaric S, Luckenbach T, Schmid A, Blaschke D, Hörz W, Korber P. 2007. Redundancy of chromatin remodeling pathways for the induction of the yeast PHO5 promoter in vivo. I Biol Chem 282: 27610-27621. doi:10.1074/jbc.M700623200

Barnhart MC, Kuich PHJL, Stellfox ME, Ward JA, Bassett EA, Black BE, Foltz DR. 2011. HJURP is a CENP-A chromatin assembly factor sufficient to form a functional de novo kinetochore. I Cell Biol 194: 229-243. doi:10.1083/jcb 201012017

Baum M, Ngan VK, Clarke L. 1994. The centromeric K-type repeat and the central core are together sufficient to establish a functional Schizosaccharomyces pombe centromere. Mol Biol Cell 5: 747-761. doi:10.1091/mbc.5.7.747

Bergmann JH, Rodríguez MG, Martins NMC, Kimura H, Kelly DA, Masumoto H, Larionov V, Jansen LET, Earnshaw WC. 2011. Epigenetic engineering shows $\mathrm{H} 3 \mathrm{~K} 4 \mathrm{me} 2$ is required for HJURP targeting and CENP-A assembly on a synthetic human kinetochore. EMBO J 30: 328-340. doi:10.1038/emboj .2010 .329

Bergmann JH, Jakubsche JN, Martins NM, Kagansky A, Nakano M, Kimura H, Kelly DA, Turner BM, Masumoto H, Larionov $\mathrm{V}$, et al. 2012. Epigenetic engineering: histone H3K9 acetylation is compatible with kinetochore structure and function. J Cell Sci 125: 411-421. doi:10.1242/jcs.090639

Bobkov GOM, Gilbert N, Heun P. 2018. Centromere transcription allows CENP-A to transit from chromatin association to stable incorporation. I Cell Biol 217: 1957-1972. doi:10 $.1083 /$ jcb. 201611087

Brahma S, Udugama MI, Kim J, Hada A, Bhardwaj SK, Hailu SG, Lee TH, Bartholomew B. 2017. INO80 exchanges H2A.Z for $\mathrm{H} 2 \mathrm{~A}$ by translocating on DNA proximal to histone dimers. Nat Commun 8: 15616. doi:10.1038/ncomms 15616

Cai Y, Jin J, Yao T, Gottschalk AJ, Swanson SK, Wu S, Shi Y, Washburn MP, Florens L, Conaway RC, et al. 2007. YY1 functions with INO80 to activate transcription. Nat Struct Mol Biol 14: 872-874. doi:10.1038/nsmb1276

Castillo AG, Mellonea BG, Partridge JF, Richardsonc W, Hamilton GL, Allshire RC, Pidoux AL. 2007. Plasticity of fission yeast CENP-A chromatin driven by relative levels of histone H3 and H4. PLoS Genet 3: e121. doi:10.1371/journal.pgen .0030121

Castillo AG, Pidoux AL, Catania S, Durand-Dubief M, Choi ES, Hamilton G, Ekwall K, Allshire RC. 2013. Telomeric repeats facilitate CENP-ACnp1 incorporation via telomere binding proteins. PLOS One 8: e69673. doi:10.1371/journal.pone .0069673

Catania S, Pidoux AL, Allshire RC. 2015. Sequence features and transcriptional stalling within centromere DNA promote establishment of CENP-A chromatin. PLoS Genet 11: e1004986. doi:10.1371/journal.pgen.1004986

Chan FL, Marshall OJ, Saffery R, Won Kim B, Earle E, Choo KHA, Wong LH. 2012. Active transcription and essential role of RNA polymerase II at the centromere during mitosis. Proc Natl Acad Sci 109: 1979-1984. doi:10.1073/pnas.1108705109

Chang C-H, Chavan A, Palladino J, Wei X, Martins NMC, Santinello B, Chen C-C, Erceg J, Beliveau BJ, Wu C-T, et al. 2019. Islands of retroelements are major components of Drosophila centromeres. PLOS Biol 17: e3000241. doi:10.1371/journal .pbio.3000241

Chen L, Cai Y, Jin G, Florens L, Swanson SK, Washburn MP, Conaway JW, Conaway RC. 2011. Subunit organization of the human INO80 chromatin remodeling complex: an evolutionarily conserved core complex catalyzes ATP-dependent nucleosome remodeling. I Biol Chem 286: 11283-11289. doi:10.1074/jbc.M111.222505

Chen CC, Dechassa ML, Bettini E, Ledoux MB, Belisario C, Heun P, Luger K, Mellone BG. 2014. CAL1 is the Drosophila CENPA assembly factor. I Cell Biol 204: 313-329.

Chen CC, Bowers S, Lipinszki Z, Palladino J, Trusiak S, Bettini E, Rosin L, Przewloka MR, Glover DM, O'Neill RJ, et al. 2015. Establishment of centromeric chromatin by the CENP-A assembly factor CAL1 requires FACT-mediated transcription. Dev Cell 34: 73-84. doi:10.1016/j.devcel.2015.05.012

Cheng Z, Dong F, Langdon T, Ouyang S, Buell CR, Gu M, Blattner FR, Jiang J. 2002. Functional rice centromeres are marked by a 
satellite repeat and a centromere-specific retrotransposon. Plant Cell 14: 1691-1704. doi:10.1105/tpc.003079

Choi ES, Strålfors A, Castillo AG, Durand-Dubief M, Ekwall K, Allshire RC. 2011. Identification of noncoding transcripts from within CENP-A chromatin at fission yeast centromeres. J Biol Chem 286: 23600-23607. doi:10.1074/jbc.M111.228510

Choi ES, Strålfors A, Catania S, Castillo AG, Svensson JP, Pidoux AL, Ekwall K, Allshire RC. 2012. Factors that promote H3 chromatin integrity during transcription prevent promiscuous deposition of CENP-A ${ }^{\text {Cnp1 }}$ in fission yeast. PLoS Genet 8: e1002985. doi:10.1371/journal.pgen.1002985

Choi ES, Cheon Y, Kang K, Lee D. 2017. The Ino80 complex mediates epigenetic centromere propagation via active removal of histone H3. Nat Commun 8: 529. doi:10.1038/s41467017-00704-3

Chueh AC, Northrop EL, Brettingham-Moore KH, Choo KHA, Wong LH. 2009. LINE retrotransposon RNA is an essential structural and functional epigenetic component of a core neocentromeric chromatin. PLOS Genet 5: e1000354. doi:10 .1371/journal.pgen.1000354

Clapier CR, Cairns BR. 2009. The biology of chromatin remodeling complexes. Annu Rev Biochem 78: 273-304. doi:10.1146/ annurev.biochem.77.062706.153223

Conaway RC, Conaway JW. 2009. The INO80 chromatin remodeling complex in transcription, replication and repair. Trends Biochem Sci 34: 71-77. doi:10.1016/j.tibs.2008.10.010

Dion MF, Kaplan T, Kim M, Buratowski S, Friedman N, Rando OJ. 2007. Dynamics of replication-independent histone turnover in budding yeast. Science 315: 1405-1408.

Duda Z, Trusiak S, O'Neill R. 2017. Centromere transcription: means and motive BT - centromeres and kinetochores: discovering the molecular mechanisms underlying chromosome inheritance. Prog Mol Subcell Biol 56: 257-281. doi:10 .1007/978-3-319-58592-5_11

Erhardt S, Mellone BG, Betts CM, Zhang W, Karpen GH, Straight AF. 2008. Genome-wide analysis reveals a cell cycle-dependent mechanism controlling centromere propagation. I Cell Biol 183: 805-818. doi:10.1083/jcb.200806038

Fachinetti D, Han JS, McMahon MA, Ly P, Abdullah A, Wong AJ, Cleveland DW. 2015. DNA sequence-specific binding of CENP-B enhances the fidelity of human centromere function. Dev Cell 33: 314-327. doi:10.1016/j.devcel.2015.03.020

Folco HD, Pidoux AL, Urano T, Allshire RC. 2008. Heterochromatin and RNAi are required to establish CENP-A chromatin at centromeres. Science 319: 94-97. doi:10.1126/science .1150944

Fukagawa T, Earnshaw WC. 2014. The centromere: chromatin foundation for the kinetochore machinery. Dev Cell 30: 496-508. doi:10.1016/j.devcel.2014.08.016

Grady DL, Ratliff RL, Robinson DL, McCanlies EC, Meyne J, Moyzis RK. 1992. Highly conserved repetitive DNA sequences are present at human centromeres. Proc Natl Acad Sci 89: 1695-1699. doi:10.1073/pnas.89.5.1695

Grenfell AW, Heald R, Strzelecka M. 2016. Mitotic noncoding RNA processing promotes kinetochore and spindle assembly in Xenopus. I Cell Biol 214: 133-141. doi:10.1083/jcb .201604029

Guarente L. 1983. Yeast promoters and lacZ fusions designed to study expression of cloned genes in yeast. Methods Enzymol 101: 181-191. doi:10.1016/0076-6879(83)01013-7

Hayashi M, Katou Y, Itoh T, Tazumi M, Yamada Y, Takahashi T, Nakagawa T, Shirahige K, Masukata H. 2007. Genome-wide localization of pre-RC sites and identification of replication origins in fission yeast. EMBO J 26: 1327-1339. doi:10.1038/ sj.emboj. 7601585
He Q, Johnston J, Zeitlinger J. 2015. ChIP-nexus enables improved detection of in vivo transcription factor binding footprints. Nat Biotechnol 33: 395-401. doi:10.1038/nbt.3121

Hill A, Bloom K. 1987. Genetic manipulation of centromere function. Mol Cell Biol 7: 2397-2405. doi:10.1128/MCB.7.7.2397

Hogan CJ, Aligianni S, Durand-Dubief M, Persson J, Will WR, Webster J, Wheeler L, Mathews CK, Elderkin S, Oxley D, et al. 2010. Fission yeast Iec1-Ino80-mediated nucleosome eviction regulates nucleotide and phosphate metabolism. Mol Cell Biol 30: 657-674. doi:10.1128/MCB.01117-09

Hori T, Shang WH, Takeuchi K, Fukagawa T. 2013. The CCAN recruits CENP-A to the centromere and forms the structural core for kinetochore assembly. J Cell Biol 200: 45-60. doi:10 $.1083 /$ jcb.201210106

Ishii K, Ogiyama Y, Chikashige Y, Soejima S, Masuda F, Kakuma T, Hiraoka Y, Takahashi K. 2008. Heterochromatin integrity affects chromosome reorganization after centromere dysfunction. Science 321: 1088-1091. doi:10.1126/science.1158699

Jansen LET, Black BE, Foltz DR, Cleveland DW. 2007. Propagation of centromeric chromatin requires exit from mitosis. J Cell Biol 176: 795-805. doi:10.1083/jcb.200701066

Kagansky A, Diego Folco H, Almeida R, Pidoux AL, Boukaba A, Simmer F, Urano T, Hamilton GL, Allshire RC. 2009. Synthetic heterochromatin bypasses RNAi and centromeric repeats to establish functional centromeres. Science 324: 1716-1719. doi:10.1126/science.1172026

Ketel C, Wang HSW, McClellan M, Bouchonville K, Selmecki A, Lahav T, Gerami-Nejad M, Berman J. 2009. Neocentromeres form efficiently at multiple possible loci in Candida albicans. PLoS Genet 5: e1000400. doi:10.1371/journal.pgen.1000400

Kipling D, Ackford HE, Taylor BA, Cooke HJ. 1991. Mouse minor satellite DNA genetically maps to the centromere and is physically linked to the proximal telomere. Genomics 11: 235-241. doi:10.1016/0888-7543(91)90128-2

Klopf E, Paskova L, Sole C, Mas G, Petryshyn A, Posas F, Wintersberger U, Ammerer G, Schuller C. 2009. Cooperation between the INO80 complex and histone chaperones determines adaptation of stress gene transcription in the yeast Saccharomyces cerevisiae. Mol Cell Biol 29: 4994-5007. doi:10.1128/MCB .01858-08

Komarnitsky P, Cho EJ, Buratowski S. 2000. Different phosphorylated forms of RNA polymerase II and associated mRNA processing factors during transcription. Genes Dev 14: 24522460. doi:10.1101/gad.824700

Kops GJPL, Weaver BAA, Cleveland DW. 2005. On the road to cancer: aneuploidy and the mitotic checkpoint. Nat Rev Cancer 5: 773-785. doi:10.1038/nrc1714

Lafon A, Taranum S, Pietrocola F, Dingli F, Loew D, Brahma S, Bartholomew B, Papamichos-Chronakis M. 2015. INO80 chromatin remodeler facilitates release of RNA polymerase II from chromatin for ubiquitin-mediated proteasomal degradation. Mol Cell 60: 784-796. doi:10.1016/j.molcel.2015.10 .028

Lermontova I, Schubert V, Fuchs J, Klatte S, Macas J, Schubert I. 2006. Loading of Arabidopsis centromeric histone CENH3 occurs mainly during G2 and requires the presence of the histone fold domain. Plant Cell 18: 2443-2451. doi:10.1105/tpc .106 .043174

Ling YH, Yuen KWY. 2019. Point centromere activity requires an optimal level of centromeric noncoding RNA. Proc Natl Acad Sci 116: 6270-6279. doi:10.1073/pnas.1821384116

Logsdon GA, Gambogi CW, Liskovykh MA, Barrey EJ, Larionov V, Miga KH, Heun P, Black B. 2019. Human artificial chromosomes that bypass centromeric DNA. Cell 178: 624-639.e19. doi:10.1016/j.cell.2019.06.006 
Marquardt S, Escalante-Chong R, Pho N, Wang J, Churchman LS, Springer M, Buratowski S. 2014. A chromatin-based mechanism for limiting divergent noncoding transcription. Cell 157: 1712-1723. doi:10.1016/j.cell.2014.04.036

Marques M, Laflamme L, Gervais AL, Gaudreau L. 2010. Reconciling the positive and negative roles of histone H2A.Z in gene transcription. Epigenetics 5: 267-272. doi:10.4161/epi.5.4 .11520

McNulty SM, Sullivan LL, Sullivan BA. 2017. Human centromeres produce chromosome-specific and array-specific a satellite transcripts that are complexed with CENP-A and CENP-C. Dev Cell 42: 226-240.e6. doi:10.1016/j.devcel.2017 .07 .001

Mellone BG, Grive KJ, Shteyn V, Bowers SR, Oderberg I, Karpen GH. 2011. Assembly of Drosophila centromeric chromatin proteins during mitosis. PLoS Genet 7: e1002068. doi:10 .1371 /journal.pgen. 1002068

Mendiburo MJ, Padeken J, Fülöp S, Schepers A, Heun P. 2011. Drosophila CENH3 is sufficient for centromere formation. Science 334: 686-690. doi:10.1126/science.1206880

Nakano M, Cardinale S, Noskov VN, Gassmann R, Vagnarelli P, Kandels-Lewis S, Larionov V, Earnshaw WC, Masumoto H. 2008. Inactivation of a human kinetochore by specific targeting of chromatin modifiers. Dev Cell 14: 507-522. doi:10 $.1016 /$ j.devcel.2008.02.001

Ohkuni K, Kitagawa K. 2011. Endogenous transcription at the centromere facilitates centromere activity in budding yeast. Curr Biol 21: 1695-1703. doi:10.1016/j.cub.2011.08.056

Ohzeki J, Shono N, Otake K, Martins NMC, Kugou K, Kimura H, Nagase T, Larionov V, Earnshaw WC, Masumoto H. 2016. KAT7/HBO1/MYST2 regulates CENP-A chromatin assembly by antagonizing Suv39h1-mediated centromere inactivation. Dev Cell 37: 413-427. doi:10.1016/j.devcel.2016.05.006

Okada T, Ohzeki J, Nakano M, Yoda K, Brinkley WR, Larionov V, Masumoto H. 2007. CENP-B controls centromere formation depending on the chromatin context. Cell 131: 1287-1300. doi:10.1016/j.cell.2007.10.045

Papamichos-Chronakis M, Watanabe S, Rando OJ, Peterson CL. 2011. Global regulation of H2A.Z localization by the INO80 chromatin-remodeling enzyme is essential for genome integrity. Cell 144: 200-213. doi:10.1016/j.cell.2010.12.021

Partridge JF, Borgstrøm B, Allshire RC. 2000. Distinct protein interaction domains and protein spreading in a complex centromere. Genes Dev 14: 783-791.

Pearson CG, Yeh E, Gardner M, Odde D, Salmon ED, Bloom K. 2004. Stable kinetochore-microtubule attachment constrains centromere positioning in metaphase. Curr Biol 14: 19621967. doi:10.1016/j.cub.2004.09.086

Perpelescu M, Nozaki N, Obuse C, Yang H, Yoda K. 2009. Active establishment of centromeric CENP-A chromatin by RSF complex. J Cell Biol 185: 397-407. doi:10.1083/jcb.200903088

Pidoux AL, Richardson W, Allshire RC. 2003. Sim4: a novel fission yeast kinetochore protein required for centromeric silencing and chromosome segregation. J Cell Biol 161: 295307. doi: $10.1083 /$ jcb. 200212110

Poli J, Gasser SM, Papamichos-Chronakis M. 2017. The INO80 remodeller in transcription, replication and repair. Philos Trans R Soc B Biol Sci 372: 20160290. doi:10.1098/rstb.2016 .0290

Rošić S, Köhler F, Erhardt S. 2014. Repetitive centromeric satellite RNA is essential for kinetochore formation and cell division. J Cell Biol 207: 335-349. doi:10.1083/jcb.201404097
Sadeghi L, Siggens L, Svensson JP, Ekwall K. 2014. Centromeric histone $\mathrm{H} 2 \mathrm{~B}$ monoubiquitination promotes noncoding transcription and chromatin integrity. Nat Struct Mol Biol 21: 236-243. doi:10.1038/nsmb.2776

Schuh M, Lehner CF, Heidmann S. 2007. Incorporation of Drosophila CID/CENP-A and CENP-C into centromeres during early embryonic anaphase. Curr Biol 17: 237-243. doi:10.1016/j .cub.2006.11.051

Shang WH, Hori T, Martins NMC, Toyoda A, Misu S, Monma N, Hiratani I, Maeshima K, Ikeo K, Fujiyama A, et al. 2013. Chromosome engineering allows the efficient isolation of vertebrate neocentromeres. Dev Cell 24: 635-648. doi:10.1016/j .devcel.2013.02.009

Shukla M, Tong P, White SA, Singh PP, Reid AM, Catania S, Pidoux AL, Allshire RC. 2018. Centromere DNA destabilizes $\mathrm{H} 3$ nucleosomes to promote CENP-A deposition during the cell cycle. Curr Biol 28: 3924-3936.e4. doi:10.1016/j.cub .2018.10.049

Tong P, Pidoux AL, Toda NRT, Ard R, Berger H, Shukla M, Torres-Garcia J, Müller CA, Nieduszynski CA, Allshire RC. 2019. Interspecies conservation of organisation and function between nonhomologous regional centromeres. Nat Commun 10: 2343. doi:10.1038/s41467-019-09824-4

Tramantano M, Sun L, Au C, Labuz D, Liu Z, Chou M, Shen C, Luk E. 2016. Constitutive turnover of histone H2A.Z at yeast promoters requires the preinitiation complex. Elife 5: e14243. doi:10.7554/eLife.14243

Udugama M, Sabri A, Bartholomew B. 2011. The INO80 ATP-dependent chromatin remodeling complex is a nucleosome spacing factor. Mol Cell Biol 31: 662-673. doi:10.1128/MCB .01035-10

Venkatesh S, Workman JL. 2015. Histone exchange, chromatin structure and the regulation of transcription. Nat Rev Mol Cell Biol 16: 178-189. doi:10.1038/nrm3941

Verzijlbergen KF, Menendez-Benito V, van Welsem T, van Deventer SJ, Lindstrom DL, Ovaa H, Neefjes J, Gottschling DE, van Leeuwen F. 2010. Recombination-induced tag exchange to track old and new proteins. Proc Natl Acad Sci 107: 64-68. doi:10.1073/pnas.0911164107

Vizcaíno JA, Csordas A, Del-Toro N, Dianes JA, Griss J, Lavidas I, Mayer G, Perez-Riverol Y, Reisinger F, Ternent T, et al. 2016. 2016 update of the PRIDE database and its related tools. Nucleic Acids Res 44: 11033. doi:10.1093/nar/gkv1145

Walfridsson J, Bjerling P, Thalen M, Yoo EJ, Park SD, Ekwall K. 2005. The CHD remodeling factor Hrp1 stimulates CENP-A loading to centromeres. Nucleic Acids Res 33: 2868-2879. doi:10.1093/nar/gki579

Watanabe S, Radman-Livaja M, Rando OJ, Peterson CL. 2013. A histone acetylation switch regulates H2A.Z deposition by the SWR-C remodeling enzyme. Science 340: 195-199. doi:10.1126/science.1229758

Xue Y, Van C, Pradhan SK, Su T, Gehrke J, Kuryan BG, Kitada T, Vashisht A, Tran N, Wohlschlege J, et al. 2015. The ino80 complex prevents invasion of euchromatin into silent chromatin. Genes Dev 29: 350-355. doi:10.1101/gad .256255 .114

Yao YL, Yang WM, Seto E. 2001. Regulation of transcription factor YY1 by acetylation and deacetylation. Mol Cell Biol 21: 5979-5991. doi:10.1128/MCB.21.17.5979-5991.2001

Yen K, Vinayachandran V, Pugh BF. 2013. SWR-C and INO80 chromatin remodelers recognize nucleosome-free regions near +1 nucleosomes. Cell 154: 1246-1256. doi:10.1016/j .cell.2013.08.043 


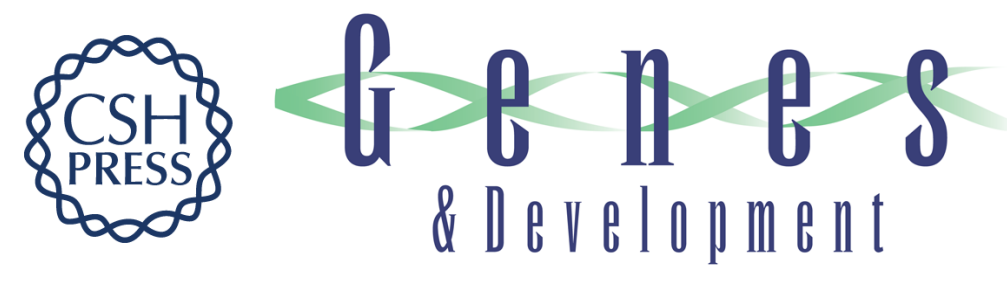

\section{Hap2-Ino80-facilitated transcription promotes de novo establishment of CENP-A chromatin}

Puneet P. Singh, Manu Shukla, Sharon A. White, et al.

Genes Dev. 2020, 34: originally published online January 9, 2020

Access the most recent version at doi:10.1101/gad.332536.119

\section{Supplemental http://genesdev.cshlp.org/content/suppl/2020/01/06/gad.332536.119.DC1 Material}

References This article cites 83 articles, 37 of which can be accessed free at: http://genesdev.cshlp.org/content/34/3-4/226.full.html\#ref-list-1

Creative This article, published in Genes \& Development, is available under a Creative Commons Commons License (Attribution 4.0 International), as described at License http://creativecommons.org/licenses/by/4.0/.

Email Alerting Receive free email alerts when new articles cite this article - sign up in the box at the top Service right corner of the article or click here.

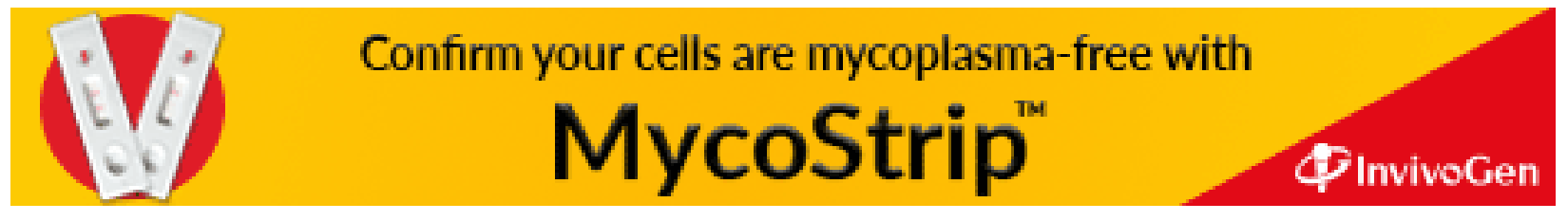

